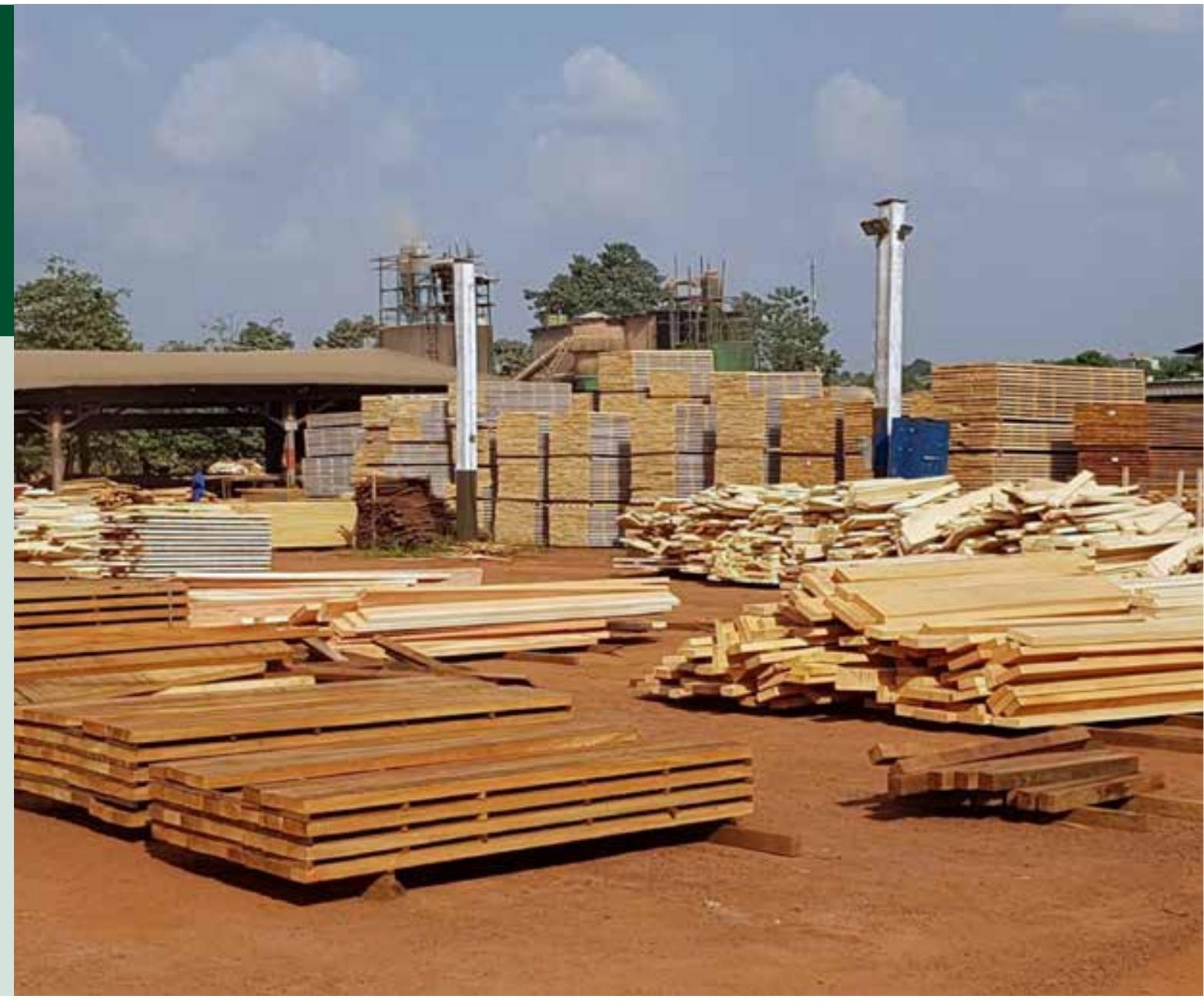

\title{
Demandes en bois et produits dérivés dans les marchés publics en Côte d'Ivoire
}

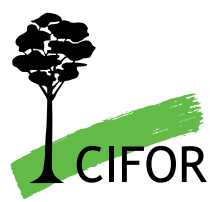




\section{Demandes en bois et produits dérivés dans les marchés publics en Côte d'Ivoire}

Raphael Tsanga

Paolo Omar Cerutti

Edouard Essiane

Centre de recherche forestière internationale

Organisation des Nations Unies pour l'alimentation et l'agriculture (FAO) et

Centre de recherche forestière internationale (CIFOR) 
Citer comme suit:

Tsanga, R., Cerutti ,P.O. et Essiane, E. 2020. Demandes en bois et produits dérivés dans les marchés publics en Côte d'Ivoire. FAO et CIFOR. https://doi.org/10.4060/cb1102fr

Les appellations employées dans ce produit d'information et la présentation des données qui y figurent n'impliquent de la part de l'Organisation des Nations Unies pour l'alimentation et l'agriculture (FAO) ni du Centre de recherche forestière internationale (CIFOR) aucune prise de position quant au statut juridique ou au stade de développement des pays, territoires, villes ou zones ou de leurs autorités, ni quant au tracé de leurs frontières ou limites. Le fait qu'une société ou qu'un produit manufacturé, breveté ou non, soit mentionné ne signifie pas que la FAO ou CIFOR approuvent ou recommandent ladite société ou ledit produit de préférence à d’autres sociétés ou produits analogues qui ne sont pas cités.

Les opinions exprimées dans ce produit d'information sont celles du/des auteur(s) et ne reflètent pas nécessairement les vues ou les politiques de la FAO ou du CIFOR.

\section{(C) $(1)(0)$}

Certains droits réservés. Cette œuvre est mise à la disposition du public selon les termes de la Licence Creative Commons Attribution-Pas d'Utilisation Commerciale-Partage dans les Mêmes Conditions 3.0 Organisations Intergouvernementales (CC BY-NC-SA 3.0 IGO; https://creativecommons.org/licenses/by-nc-sa/3.0/igo/legalcode.fr).

Selon les termes de cette licence, cette œuvre peut être copiée, diffusée et adaptée à des fins non commerciales, sous réserve que la source soit mentionnée. Lorsque l'œuvre est utilisée, rien ne doit laisser entendre que la FAO cautionne tels ou tels organisation, produit ou service. L'utilisation du logo de la FAO n'est pas autorisée. Si l'œuvre est adaptée, le produit de cette adaptation doit être diffusé sous la même licence Creative Commons ou sous une licence équivalente. Si l'œuvre est traduite, la traduction doit obligatoirement être accompagnée de la mention de la source ainsi que de la clause de non-responsabilité suivante: «La traduction n'a pas été réalisée par l'Organisation des Nations Unies pour l'alimentation et l'agriculture (FAO). La FAO n'est pas responsable du contenu ni de l'exactitude de la traduction. L'édition originale [langue] est celle qui fait foi.»

Tout litige relatif à la présente licence ne pouvant être résolu à l'amiable sera réglé par voie de médiation et d'arbitrage tel que décrit à l'Article 8 de la licence, sauf indication contraire contenue dans le présent document. Les règles de médiation applicables seront celles de l'Organisation mondiale de la propriété intellectuelle (http://www.wipo.int/amc/fr/mediation/rules) et tout arbitrage sera mené conformément au Règlement d'arbitrage de la Commission des Nations Unies pour le droit commercial international (CNUDCI).

Matériel attribué à des tiers. Il incombe aux utilisateurs souhaitant réutiliser des informations ou autres éléments contenus dans cette œuvre qui y sont attribués à un tiers, tels que des tableaux, des figures ou des images, de déterminer si une autorisation est requise pour leur réutilisation et d'obtenir le cas échéant la permission de l'ayant-droit. Toute action qui serait engagée à la suite d'une utilisation non autorisée d'un élément de l'œuvre sur lequel une tierce partie détient des droits ne pourrait l'être qu'à l'encontre de l'utilisateur.

Ventes, droits et licences. Les produits d'information de la FAO sont disponibles sur le site web de la FAO (www.fao.org/publications) et peuvent être obtenus sur demande adressée par courriel à: publications-sales@ fao.org. Les demandes visant un usage commercial doivent être soumises à: www.fao.org/contact-us/licencerequest. Les questions relatives aux droits et aux licences doivent être adressées à: copyright@fao.org. 


\section{Table des matières}

Abréviations, sigles et acronymes $\quad$ v

Remerciements $\quad$ vi

Résumé exécutif vii

1 Introduction $\quad 1$

2 Méthodes $\quad 5$

2.1 Estimation de la consommation de sciages et produits dérivés par les entités publiques

2.2 Caractérisation de la production des artisans menuisiers $\quad 7$

2.3 Estimation de la production et du coût des sciages d'origine légale 8

2.4 Limites de l'étude 8

3 Résultats $\quad \mathbf{9}$

3.1 Analyse juridique de la prise en compte de la légalité et la durabilité des produits forestiers dans les marchés publics $\quad 9$

3.2 Consommation de sciages et de meubles en bois par les marchés publics $\quad 16$

3.3 Production des meubles dans les entreprises artisanales de bois 20

3.4 Offres de bois légal disponibles sur le marché domestique 25

4 Conclusion et recommandations pour l'approvisionnement du marché local en bois légal

4.1 Optimiser l'utilisation de la ressource existante 34

4.2 Diminuer les coûts de revient des sciages industriels 35

4.3 Fluidifier la chaîne d'approvisionnement du bois légal 35

4.4 Envisager la mise en place d'une politique publique d'achat de bois légal 36

$\begin{array}{lll}5 & \text { Références } & 37\end{array}$ 


\section{Figures et tableaux}

\section{Figures}

2.1 Sites de l'étude $\quad 6$

3.1 Volumes moyens / marchés $\quad 17$

3.2 Nombre moyen de marchés par entité $\quad 17$

$\begin{array}{lll}3.3 & \text { Consommation annuelle de sciages } & 17\end{array}$

3.4 Importations de meubles en Côte d'Ivoire $\quad 18$

$\begin{array}{lll}3.5 & \text { Typologie des achats publics de mobiliers } & 19\end{array}$

$\begin{array}{ll}3.6 & \text { Création de nouveaux ateliers }\end{array}$

3.8 Spécialisation des menuiseries $\quad 21$

3.7 Type de métiers dans les menuiseries $\quad 21$

3.9 Âge des équipements $\quad 21$

3.10 Qualité des sciages utilisés $\quad 24$

3.11 Principales essences utilisées $\quad 24$

3.12 Législation sur la provenance du bois $\quad 26$

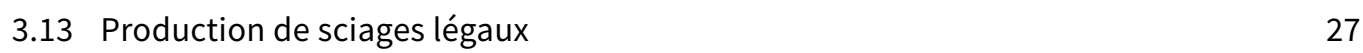

$\begin{array}{ll}3.14 & \text { Ventes locales de sciages industriels }\end{array}$

3.15 Prix des sciages à l'exportation 28

3.16 Principales essences commercialisées $\quad 29$

3.17 Prix de vente moyen des sciages sur le marché local 29

\section{Tableaux}

3.1 Types de produits $\quad 23$

3.2 Coûts de revient des sciages industriels (exportations) 30

3.3 Coûts de revient des sciages industriels (ventes locales) 31 


\section{Abréviations, sigles et acronymes}

AFD

AMP

APV

BAD

BTP

CCT

CFA

CIFOR

EBR

EIE

FAO

FC

FLEGT

FMI

GATT

GIZ

INS

MINEF

MCPD

OCDE

ODD

OIBT

OMC

PEF

PIB

PME

PNUD

PTF

SODEFOR

TVA

UEMOA

UTB
Agence française de développement

Accord sur les marchés publics

Accord de partenariat volontaire

Banque africaine de développement

Bâtiment et travaux publics

Cahier des clauses techniques particulières

Communauté financière en Afrique

Centre de recherche forestière internationale

Équivalent bois rond

Étude d'impact environnemental

Organisation des Nations Unies pour l'alimentation et l'agriculture Forêt classée

Plan d'action pour l'application des règlementations forestières, gouvernance et échanges commerciaux

Fonds monétaire international

Accord général sur les tarifs douaniers et le commerce

Coopération technique allemande

Institut national de la statistique

Ministère des eaux et forêts

Modes de consommation et de production durables

Organisation de coopération pour le développement économique

Objectifs pour le développement durable

Organisation internationale des bois tropicaux

Organisation mondiale du commerce

Périmètre d'exploitation forestière

Produit intérieur brut

Petites et moyennes entreprises

Programme des nations unis pour le développement

Partenaires techniques et financiers

Société de développement des forêts

Taxe sur la valeur ajoutée

Union économique et monétaire ouest-africaine

Unités de transformation de bois 


\section{Remerciements}

Ce document présente les résultats d'une étude financée par le programme FAO-UE FLEGT dans le cadre du projet intitulé « Réalisation d'une étude de caractérisation des différents types d'offres et de demandes en bois et produits dérivés dans les marchés publics en Côte d'Ivoire ». Ce document a été rendu possible grâce au soutien incommensurable de nombreuses personnes : celles qui ont contribué par leurs connaissances, en donnant de leur précieux temps et en fournissant la documentation (personnes interrogées dans les ministères, les agences gouvernementales, les collectivités territoriales, artisans menuisiers, directeurs et employés des entreprises d'exploitation forestière qui ont bien voulu participer à cette étude) celles qui ont attentivement relu les premières versions de ce rapport (Emmanuel Heuse, Sarah Fumey, Sylla Cheick Tidiane). Au cours de cette enquête, la collaboration du secrétariat technique permanent FLEGT, des services centraux et déconcentrés du ministère des eaux et forêts et d'un grand nombre de personnes-ressources dans les villes comme dans les zones rurales a permis à létude de se dérouler sans difficultés.

Cette publication résulte du projet « Réalisation d'une étude de caractérisation des différents types d’offres et de demandes en bois et produits dérivés dans les marchés publics en Côte d'Ivoire » financé par le programme FAO-UE FLEGT et mis en oeuvre par le CIFOR dans le cadre des activités du Programme de recherche du CGIAR sur les forêts, les arbres et l'agroforesterie (FTA). 


\section{Résumé exécutif}

Depuis 2013, la Côte d'Ivoire est engagée dans la négociation d'un Accord de partenariat volontaire (APV) avec l'Union européenne (UE) dont l'objectif est d'endiguer l'exportation de bois d'origine illégale vers l'UE et la circulation de celui-ci sur le marché national. En ce qui concerne le marché national, on estime quà l'heure actuelle la part de sciages d'origine illégale représente approximativement 73 pour cent des 1,9 million de $\mathrm{m}^{3}$ de sciages qui circulent sur le marché domestique de Côte d'Ivoire. L'État et les collectivités territoriales contribuent indirectement à cette exploitation illégale à travers la consommation des produits forestiers dorigine incertaine dans le cadre des marchés publics. L'État ivoirien étant désormais engagé dans la lutte contre les produits forestiers d’origine illégale, la commande publique a vocation à devenir un levier puissant permettant d'augmenter la demande en sciages légaux et contribuer à la formalisation de la filière artisanale de bois.

Ce rapport a pour objectif d'informer les décisions techniques et politiques sur les caractéristiques de la demande publique de sciages et les volumes consommés. Le rapport donne également des orientations pouvant permettre d'augmenter l'offre et la consommation publique de bois légal. Tout ceci s'inscrit dans le cadre de la réflexion initiée par l'État ivoirien sur la mise en place d'une politique d'achat de bois responsable, légal et durable.

La question de la légalité des produits forestiers est aujourd'hui prise en compte par la nouvelle loi forestière de 2019 et par ses textes d'application en cours d'adoption. Mais elle n'est pas abordée de manière pratique et opérationnelle quand l'État doit lui-même s'impliquer comme acteur dans le marché du bois. Les enjeux pratiques de légalité doivent aujourd'hui dépasser le cadre juridique sectoriel pour être déclinés dans l'ensemble des politiques et des pratiques publiques.

L'évolution en direction de l'accroissement de la prise en compte de la légalité en dehors du secteur forestier a été amorcée par la consécration de la notion d'achat durable dans le nouveau code des marchés publics de 2019. Nonobstant cette évolution conceptuelle, la réglementation actuelle ne tient pas encore compte du critère de légalité dans les bois utilisés dans les chantiers publics. Les principes qui gouvernent la passation des marchés publics accordent davantage d'importance à la transparence de la procédure, à la libre concurrence entre les prestataires et à la recherche du meilleur rapport qualité-coût. Il n'existe donc pas de stratégie formelle ou informelle de promotion de la légalité du bois dans les marchés publics. Cette réalité concerne d’ailleurs aussi bien l'État que les partenaires techniques et financiers présents en Côte d'Ivoire.

Or ce levier est potentiellement très important pour promouvoir la légalité des approvisionnements en bois sur le marché domestique. Même si les données existantes et les méthodes de collecte de ces données par les administrations doivent être améliorées, les analyses conduites dans le cadre de cette étude permettent de dégager certaines tendances. Elles indiquent que sur la période 2015-2018, les marchés publics ont absorbé en moyenne environ $342000 \mathrm{~m}^{3}$ en équivalent bois rond, répartis entre l'État et les collectivités territoriales. L'essentiel de la consommation publique de sciages est constitué de travaux de construction et de réhabilitation des infrastructures. 
Selon les dispositions réglementaires antérieures au Code forestier de 2019 en vigueur à titre transitoire, le bois légal est susceptible de provenir de deux types de titres d'exploitation forestière: les périmètres d'exploitation forestière et les plantations. La production annuelle moyenne de ces deux sources est d'environ $322000 \mathrm{~m}^{3}$ de sciages dont la grande majorité est exportée vers les marchés occidentaux. Les sciages légaux font face à de réels problèmes de compétitivité sur le marché local. Les prix de vente des sciages industriels à l'exportation sont entre 70 et 80 pour cent plus élevés que ceux pratiqués sur le marché local, ce qui les met quasiment hors de portée de la majorité de la demande nationale. Le coût de revient d'un mètre cube de sciage industriel est estimé à environ $239000 \mathrm{XOF}$, alors que celui de sciage informel revient à environ $105000 \mathrm{XOF}$. Avec de tels écarts, il est peu probable que les sciages industriels soient compétitifs sur le marché local face à des sciages artisanaux qui ne sont pas assujettis à l'impôt et surtout en l'absence de sensibilité pour les produits légaux ou durables de la part des consommateurs. Les résultats montrent que des industriels mettent du bois légal sur le marché local au prix usine de $115000 \mathrm{XOF}$ par $\mathrm{m}^{3}$. Mais certains dysfonctionnements le long de la chaîne de valeur comme la monopolisation de la filière par les intermédiaires contribuent à renchérir le prix des produits dans les marchés urbains.

La demande publique se singularise par l'utilisation indirecte de sciages dans le cadre de la construction ou la réhabilitation des infrastructures et par l'acquisition de biens déquipement, dont une partie non négligeable requiert un approvisionnement en bois. L'autre caractéristique de la demande publique de mobilier est une préférence marquée pour le mobilier importé principalement des pays asiatiques et de la Turquie. Ce mobilier dont la durabilité a régulièrement été mise en cause pendant la phase d'enquête, est en revanche largement plébiscité pour ses qualités de confort et de stabilité. Ce marché est en plein essor puisque la progression des importations de meubles tout type confondu a quasiment quadruplé en l'espace de dix ans, passant de 7 à 27 milliards de XOF.

Cette commande publique échappe en grande partie aux fabricants locaux de meubles et particulièrement les artisans-menuisiers. En dépit de l'existence de quelques menuiseries qui offrent des produits de très haute qualité, le type de produits proposé ne correspond pas dans la majorité des cas aux besoins des autorités publiques et ce à la fois sur le plan des volumes concernés, de la standardisation, des spécifications techniques, et de la qualité des produits disponibles.

En ce qui concerne la qualité de l'offre, plusieurs problèmes sont à considérer. Le premier, et le plus souvent invoqué, porte sur le séchage du bois. En l'état actuel, l’absence de séchoir dans les sites de production des meubles par les menuisiers impacte négativement la stabilité des produits. Ce souci constitue une des raisons du manque de confiance des autorités publiques quant aux capacités professionnelles des menuisiers.

Deuxièmement, les artisans n'ont pas les compétences techniques qui leur permettraient d'améliorer qualitativement leur offre de produits (standardisation, respect des cahiers des charges techniques, capacité de respect des délais pour des volumes significatifs) et de gagner en compétitivité. La troisième contrainte est la difficulté d'accès à une matière première de qualité auprès des industriels. Ces différentes contraintes suggèrent qu'un très faible nombre d’entreprises artisanales sont en capacité technique et financière de répondre aux exigences de la commande publique. 
La faible pénétration des bois légaux dans la sphère publique est révélatrice de la faible disponibilité du bois légal dans les marchés locaux. Transformer les modes de consommation publics suppose, au préalable, une augmentation de l'approvisionnement du marché local en sciages légaux. Plusieurs options techniques et politiques sont envisageables pour agir sur les volumes et les coûts de production. Les mesures possibles consistent à:

- Optimiser l'utilisation de la ressource existante. Dans un contexte de rareté de la ressource, les rebuts de l'exploitation forestière doivent être mieux valorisés afin de renforcer l'offre de bois existante. Plusieurs scénarios sont envisageables parmi lesquels l'autorisation d'exploitation des rebuts par les industriels ou encore l'autorisation des exploitants artisanaux ou des exploitants semi-industriels à récupérer les rebuts à l'intérieur des PEF sous le contrôle de l'administration ou des titulaires de périmètre ou à l'extérieur des PEF. Le deuxième niveau d'optimisation de l'utilisation de la ressource disponible porte sur les chutes de bois. Plusieurs sites industriels disposent des équipements permettant la fabrication du bois de récupération.

- Diminuer les coûts de revient des sciages industriels. Des incitations fiscales sont envisageables pour les produits à destination du marché local. Celles-ci doivent être couplées avec l'encouragement des groupements d'exploitants à approvisionner les usines situées dans leur environnement immédiat de manière à diminuer les coûts de transport. Sur ce point précis, les unités industrielles ont maintenu un fonctionnement similaire à la période où la matière première était disponible. Loutil industriel n'a donc pas suffisamment évolué pour prendre en compte la nouvelle configuration du secteur forestier. Un redimensionnement des unités de production industrielle aurait pour effet d'agir sur les coûts.

- Fluidifier la chaîne d'approvisionnement du bois légal. La chaîne d'approvisionnement se distingue par les positions monopolistiques occupées par les négociants qui détiennent un pouvoir d'immobilisation important du fait de leurs capacités financières. Lacquisition préemptive de la matière première génère inévitablement des coûts supplémentaires pour le consommateur final. Il faudrait par conséquent poser les bases d'un partenariat entre le secteur industriel et celui des artisans menuisiers. Ce partenariat peut prendre la forme de centrales d'achats auprès desquelles les artisansmenuisiers pourraient s'approvisionner.

- Mettre en place une politique publique d'achat de bois légal. Une des approches qui pourrait améliorer l'offre de bois légal sur le marché est la mise en place d'une politique publique d'achat qui obligerait ou inciterait les contractants de l'État et ses démembrements techniques ou territoriaux à s'approvisionner auprès de sources autorisées lorsqu'ils sont amenés à utiliser le bois dans l'exécution des marchés publics. La mise en place d'une telle politique fera nécessairement face à au moins trois défis: (i) le problème d'une offre de bois légal relativement faible et à des coûts prohibitifs, (ii) des surcoûts potentiels pour le budget de l'État et des collectivités locales, et (iii) le risque de captation de cette niche commerciale par les industriels et l'exclusion des opérateurs de la filière artisanale. 


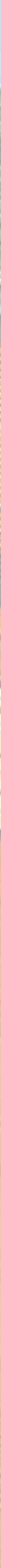




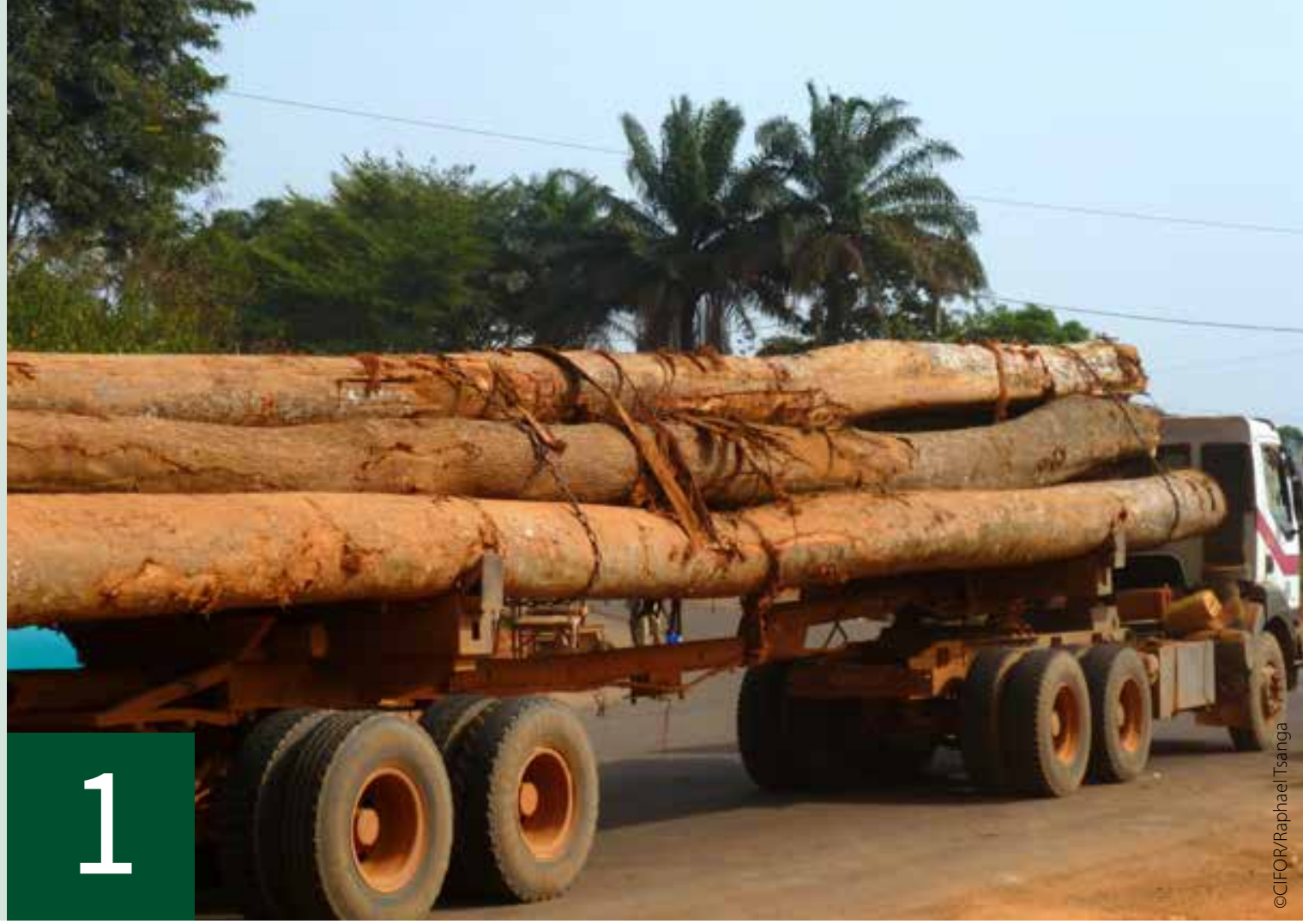

\section{Introduction}

L'émergence du concept de marché public écologique traduit la prise de conscience de l'importance économique de la commande publique. Bien que la notion de marché public écologique soit relativement récente, l'importance économique des marchés publics n'est pas une donnée nouvelle comme le montre la signature, dès 1979, d'un accord sur les marchés publics dans le cadre de l'Accord général sur les tarifs douaniers et le commerce (GATT). En vertu de cet accord sur les marchés publics (AMP) dont la version la plus récente est entrée en vigueur 2014, les États partie ont accès à des marchés publics dont le potentiel est d'environ 1700 milliards de dollars américains (OMC, 2019). Selon l'OCDE, dans un pays comme le Maroc, l'ensemble de la commande publique représente 16 pour cent du PIB, tandis que dans l'Union européenne, c'est environ 14 pour cent du PIB qui est consacré aux approvisionnements et marchés de travaux publics (Commission européenne, 2017; OCDE, 2008). Depuis l'expérience des Pays-Bas en 1991 qui font office de pionnier en la matière, le concept de marché public écologique a été opérationnalisé dans plusieurs pays, majoritairement européens, au point de devenir un axe fondamental des politiques environnementales (Commission européenne, 2008; Kataoka, 2006; Testa et al., 2012). 
La logique sous-jacente aux marchés publics écologiques est que les autorités publiques peuvent améliorer la protection de l'environnement en utilisant leur important pouvoir d'achat pour influencer le type de biens et services à acquérir (Canada et Conseil du trésor, 2018). Les marchés publics écologiques renvoient à «un processus de passation de marchés dans le cadre duquel les pouvoirs publics cherchent à obtenir des biens, des services et des travaux dont l'incidence sur l'environnement sur toute leur durée de vie sera moindre que dans le cas de biens, services et travaux à vocation identique mais ayant fait lobjet de procédures de passation de marchés différentes» (Commission européenne, 2016, 2008). En comparaison avec d'autres procédés d'acquisition ou marchés de travaux, les achats écologiques tentent de diminuer dans la mesure du possible l'incidence sur l'environnement (PNUD, 2008).

Avec une croissance moyenne de 8,7 pour cent, l'économie de la Côte d'Ivoire s'est révélée l'une des plus performantes parmi les pays pré-émergents au cours de la période 20122018 (FMI, 2019). Les moteurs de cette croissance reposent entre autres sur une demande intérieure solide, sur les performances du secteur de la construction soutenues par les grands projets d'infrastructures publics et sur l'essor du secteur immobilier (Banque mondiale, 2019; FMI, 2019). Cette tendance est appelée à se poursuivre au vu des objectifs stratégiques du plan national de développement 2015-2020 qui ambitionne de faire de la Côte d'Ivoire un pays à revenu intermédiaire à court terme.

La commande publique joue un rôle décisif dans cette dynamique de croissance à travers l'injection de ressources financières conséquentes dans léconomie ivoirienne. Les marchés publics mobilisent une part importante de l'activité du secteur privé national. Leur impact sur le secteur forestier est potentiellement très important car le bois est d'une part une matière première essentielle pour l'exécution de la plupart des travaux publics d'infrastructures, et d'autre part lorsque les marchés portent sur l'acquisition de biens mobiliers. Le marché local constitue la principale source d'approvisionnement en matériau bois pour l'État et les partenaires privés engagés dans les marchés publics. Longtemps négligés par les politiques forestières nationales et internationales et absents des statistiques officielles, les marchés domestiques de bois d'œuvre occupent une place déterminante dans l'économie de nombreux pays d’Afrique subsaharienne. Lapprovisionnement des marchés domestiques est assuré en grande majorité par un secteur artisanal faiblement réglementé et dont les processus de production sont souvent peu respectueux des exigences légales et des prescriptions d'aménagement durable (Cerbu, 2016).

En 2013, le gouvernement ivoirien a édicté un décret portant interdiction de l'exploitation et la commercialisation du bois d'œuvre en dehors des règles fixées par le code forestier et les textes subséquents (République de Côte d'Ivoire, 2013). L'engagement dans la négociation d'un APV avec l'UE s'inscrit dans la dynamique amorcée par le pays en vue de contribuer à l'endiguement de la circulation de bois illicites et des produits dérivés dans ses exportations vers l'UE mais aussi sur son marché intérieur, le gouvernement ayant choisi d'insérer ce dernier dans son APV (Cerutti et al., 2015). Des études récentes sur les échanges commerciaux portant sur le bois d'œuvre qui alimentent le marché national et sous-régional ont en effet montré que ce marché est dominé par une production artisanale essentiellement informelle, voire illégale largement. Celle-ci est supérieure à la production mise sur le marché domestique par les opérateurs du secteur industriel (Atyi et al., 2016; Louppe et Ouattara, 2013). 


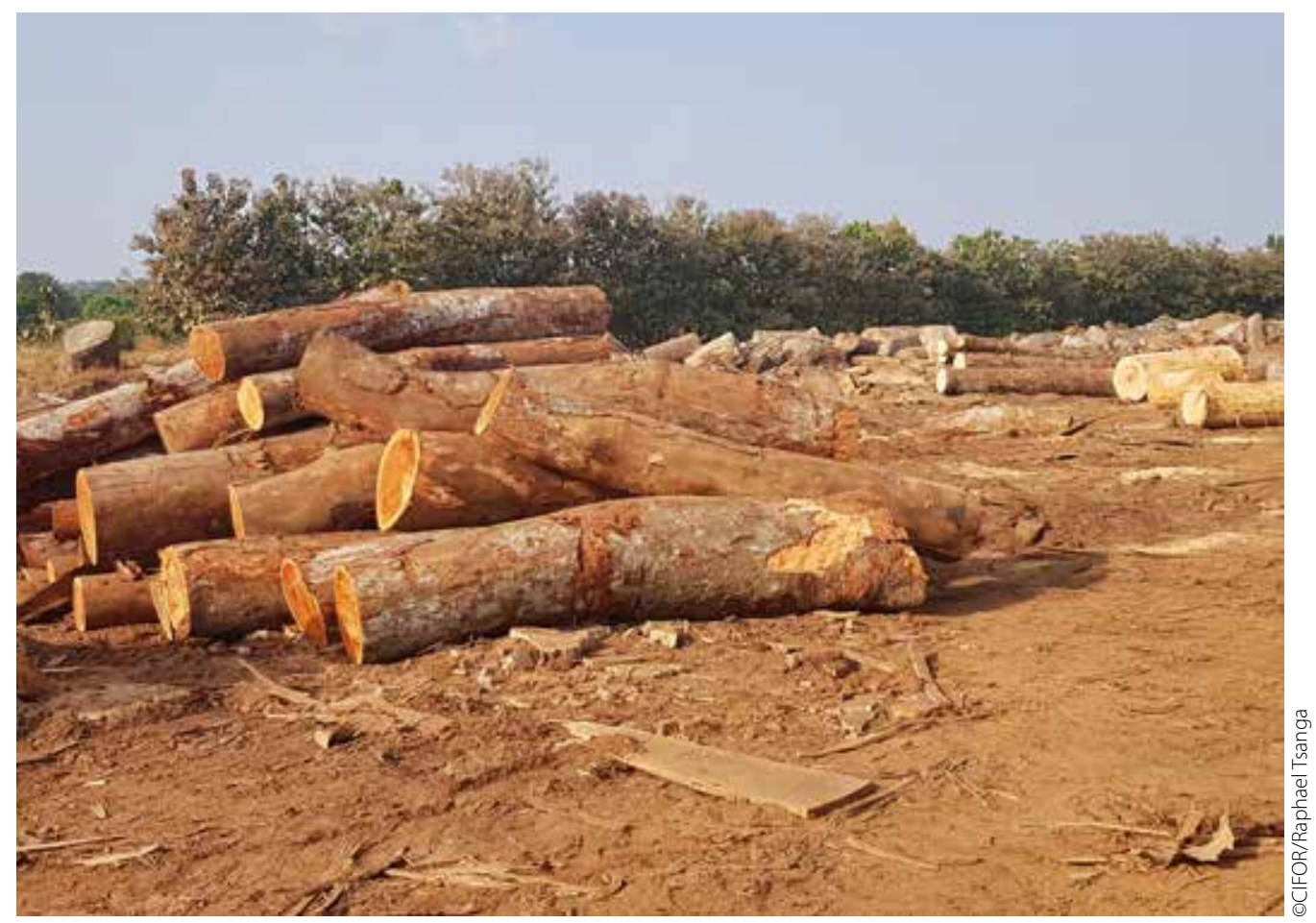

Aperçu d'un parc à bois

Mobiliser les marchés publics comme instrument de lutte contre l'exploitation forestière illégale est un défi pour les autorités publiques, au regard des implications d'une telle démarche pour les finances publiques. La place centrale de l'État dans l'activité économique en fait un acteur susceptible de jouer un rôle moteur dans l'accélération d'une demande nationale de sciages déjà en pleine expansion. L’expérience des pays du bassin du Congo montre que la consommation des sciages par les États et le secteur public en général est potentiellement importante mais très mal connue, et que la légalité, voire la durabilité des produits forestiers, ne sont pas toujours des éléments décisifs dans la commande publique (Lescuyer et al., 2016). Dans les pays développés, la notion de marché public écologique apparaît relativement bien ancrée dans les règles d'acquisition des biens par les États et les entreprises, ainsi que dans les règles commerciales (Lescuyer et al., 2016; Nogueron et Cheung, 2014). Mais dans le cas de la Côte d'Ivoire comme pour d'autres pays africains, les références à la notion d'achat écologique ou durable appliquées aux marchés publics sont relativement anecdotiques. La présente étude a pour objectif de montrer comment une meilleure prise en compte des exigences de légalité dans les marchés publics de Côte d'Ivoire pourrait permettre de concourir aux objectifs officiels d'amélioration de la gestion durable et à la reconstitution graduelle des massifs forestiers du pays. Quatre questions principales ont structuré cette étude:

1. Dans quelle mesure les exigences relatives à la légalité du bois d'œuvre sont-elles prises en compte dans la commande publique? 
2. Quelle est la consommation publique de sciages (en volume) ?

3. Quelles sont les caractéristiques de la demande publique - État et collectivités locales en bois et produits dérivés et dans quelle mesure cette demande est-elle compatible avec l'offre disponible - qualitativement et quantitativement - sur le plan local ?

4. Quels sont les différents types d’offre de bois sur le marché national ?

La caractérisation de la demande publique en bois et produits dérivés s'est déroulée suivant la méthodologie présentée dans la section suivante, laquelle s'est focalisée sur (i) l'estimation de la consommation de sciages et produits dérivés par les entités publiques, (ii) l'identification des offres de bois existantes sur le marché local et l'estimation de la production et du coût des sciages d’origine légale. La section suivante présente les résultats obtenus et la dernière énonce des recommandations sur les possibilités d'accroissement de loffre de bois légal sur le marché national.

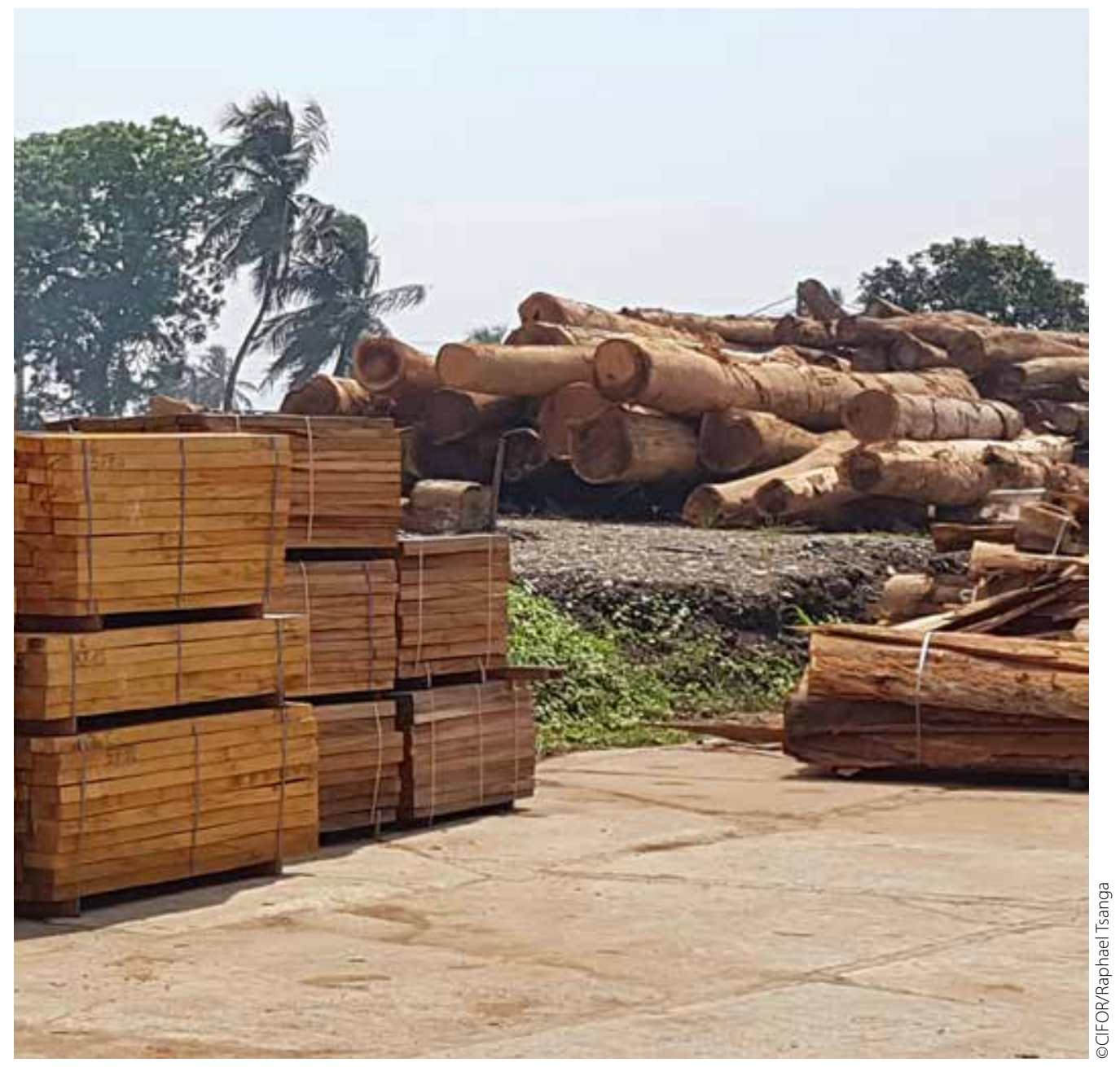

Séchage naturel de colis de bois 
de l'hygiène publique, Ministère de la construction, du logement et de l'urbanisme, Ministère de léducation nationale, de l'enseignement technique et de la formation professionnelle. Au rang des collectivités territoriales décentralisées, 12 régions y compris les districts autonomes d'Abidjan et Yamoussoukro sur les 30 que compte la Côte d'Ivoire ont été sollicités au cours des enquêtes, de même que 21 communes (figure 2.1). Sur les 39 structures contactées, trois départements ministériels, huit régions et cinq communes ont fourni des données sur leur consommation de sciages et produits dérivés.

La consommation de sciages a été évaluée sur la base de deux volets distincts. Un premier volet s'est focalisé sur l'utilisation des sciages dans la construction et la réhabilitation des bâtiments et infrastructures publiques. Le second volet s'est attelé à identifier et caractériser les acquisitions de l'État et des collectivités territoriales décentralisées nécessitant l'utilisation du bois comme matière première. Dans les deux cas, des formulaires ont été utilisés pour quantifier les volumes de bois consommés par chacune des entités ciblées et déterminer leur valeur financière. Les sources d'information mobilisées à cet effet sont les marchés publics régulièrement attribués au cours des exercices budgétaires 2015, 2016, 2017 et 2018 dans une certaine mesure. Préalablement à la collecte des données quantitatives, une phase

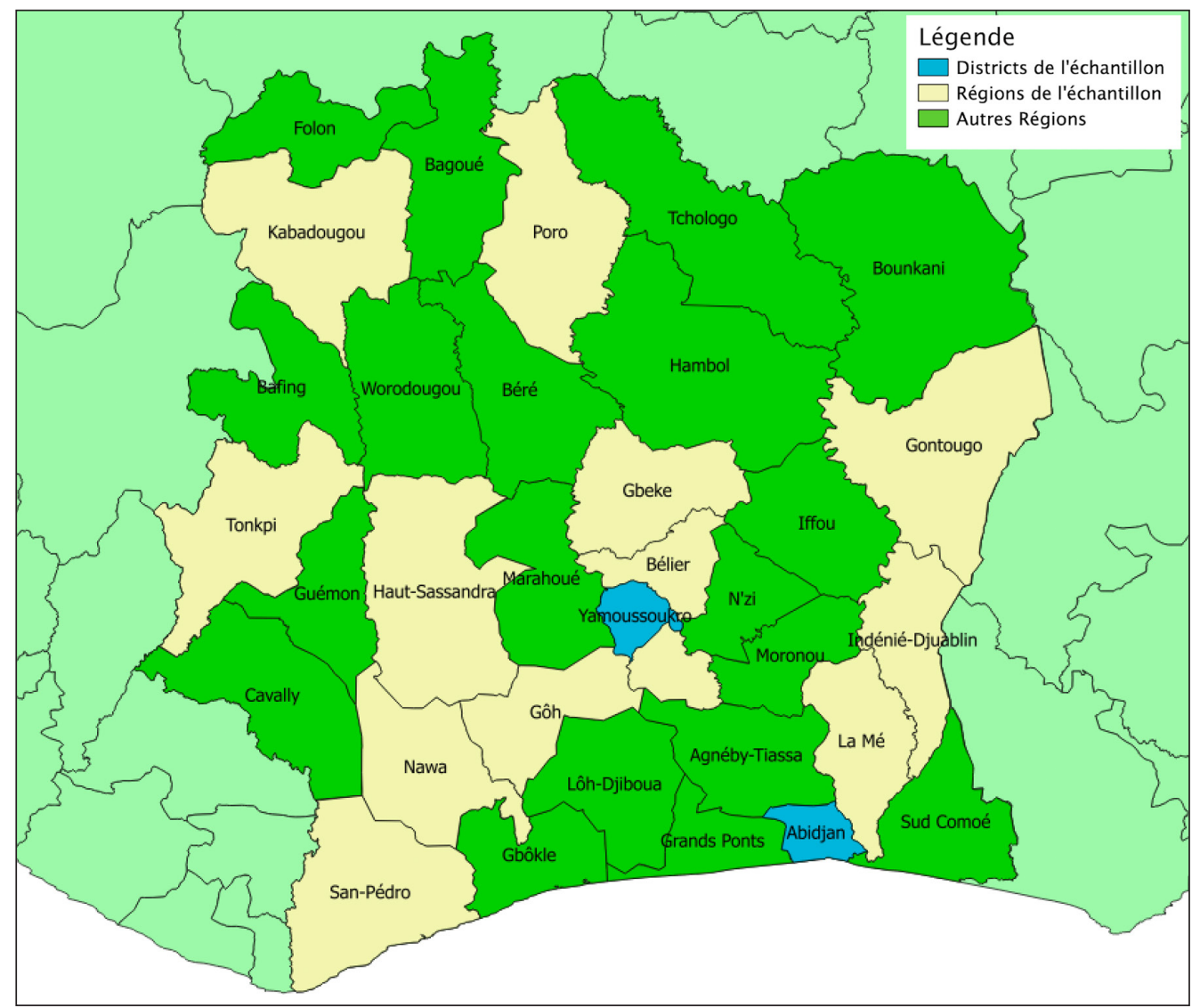

Figure 2.1 Sites de l'étude

Sources: https://data.humdata.org/dataset/cote-d-ivoire-administrative-level-0-3-boundaries-and-points 


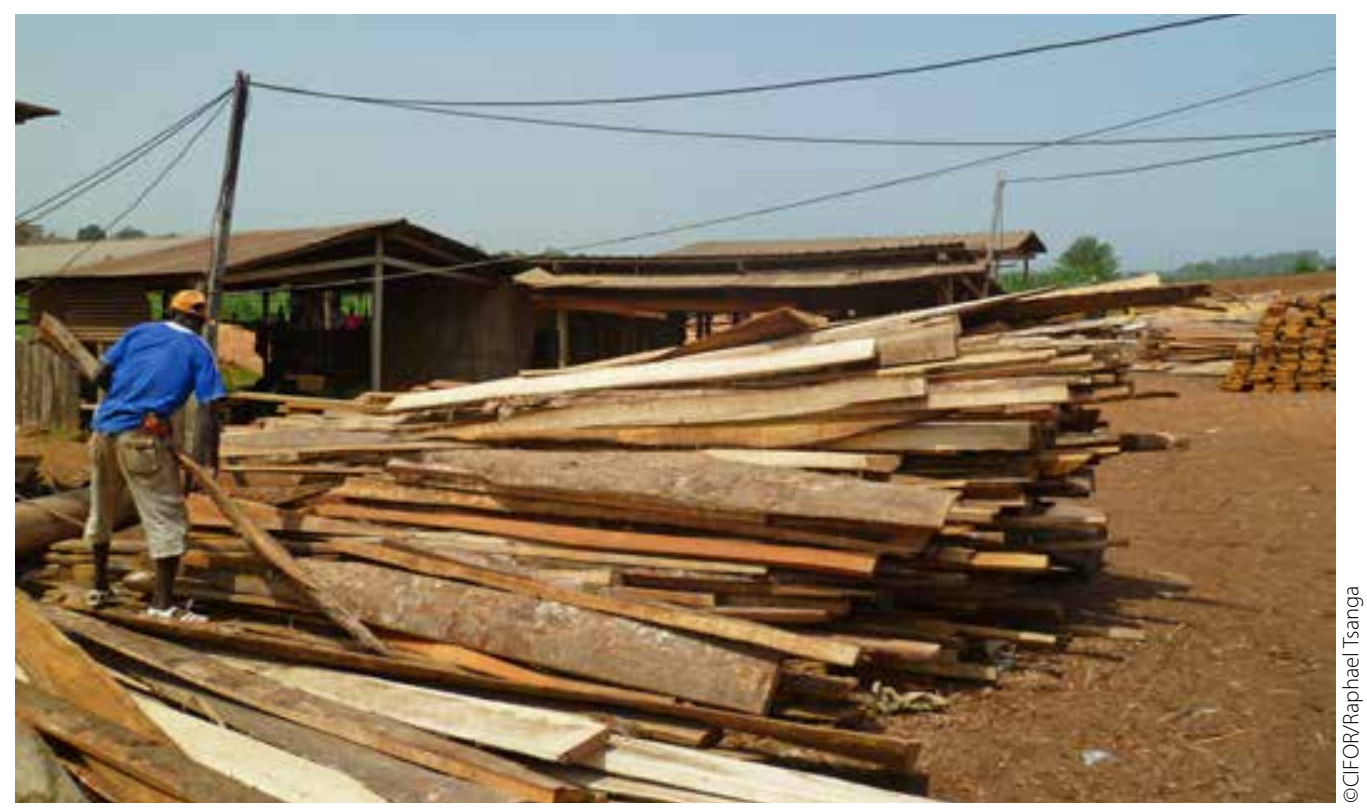

Rebuts de scierie dans un marché

qualitative faite d'entretiens a été réalisée. Les échanges ont porté sur l'existence de stratégies ou de politiques d'achat responsables, la mise en ouvre effective de ces politiques, le caractère réaliste du développement de ces politiques en cas d'inexistence, ainsi que l'adhésion des entités publiques à la mise en place d'une telle initiative.

Des organismes internationaux et agences de coopération bilatérale (Banque mondiale, Agence française de développement, Délégation de l'Union européenne, Banque africaine de développement, coopération allemande et chinoise, FAO) ont été sollicités afin de vérifier l'existence et la mise en œuvre effective de politiques d'approvisionnement responsable de bois par les partenaires techniques et financiers. Dans cette dernière catégorie, seuls deux organismes internationaux ont donné suite aux entretiens.

\subsection{Caractérisation de la production des artisans menuisiers}

La caractérisation de la production des artisans menuisiers a été construite sur base de la collecte de deux types de données nécessaires à l'analyse.

- En premier lieu, l'adéquation entre la production locale et les besoins de l'État en termes de mobilier et produits dérivés du bois. Il s'est donc agi d'identifier les spécialités et les principaux produits fabriqués par ces artisans menuisiers suivant des catégories préétablies, notamment l'ameublement, les matériaux de chantier et de construction pour les bâtiments et les travaux publics, ainsi que les huisseries (portes, fenêtres, moulures, chambranles). Cette phase de collecte de l'information s'est déroulée pendant un mois dans trois communes d'Abidjan (Abobo, Yopougon et Treichville) et à Bouaké. 
- Par la suite, nous avons évalué la capacité des artisans menuisiers à fabriquer des produits de qualité, notamment dans le secteur de l'ameublement et des huisseries. Une visite préalable des administrations publiques avait en effet permis de constater la domination des marchés publics de mobilier par des produits d'importation en provenance d'Asie et d'Europe. Il s'agissait ici de savoir si les artisans-menuisiers seraient en capacité de mettre à la disposition de l'État et des collectivités locales des produits pouvant concurrencer les importations de mobilier en termes de qualité. Suivant une approche expérimentée dans les analyses de la chaîne de valeur des filières informelles de bois d'œuvre, les informations récoltées ont en priorité ciblé les opérations conduites au cours des deux derniers mois, du fait de leur proximité avec la réalité dans un contexte d’absence de véritable comptabilité (Lescuyer et al., 2016).

\subsection{Estimation de la production et du coût des sciages d'origine légale}

L'estimation de la production de bois d’origine légale s’est faite suivant deux procédés. D’abord, la production de bois provenant de sources régulièrement autorisées par la loi forestière et les réglementations associées a été réalisée sur la base d'une analyse documentaire, notamment les statistiques de production fournies par le Ministère des eaux et forêts. L'estimation de la production de bois légal a ensuite été complétée par des rencontres avec les opérateurs et les syndicats de la filière bois afin d'estimer les coûts de revient de ces produits une fois arrivés sur le marché national. Au total, 13 unités de transformation ont été visitées à travers le pays. L'un des problèmes posés par l’offre des produits d’origine légale sur le marché local est incontestablement celui de leur compétitivité face aux sciages d'origine informelle. Lestimation de la production et des prix de cette dernière catégorie de sciages procède des travaux précédemment conduits par le CIFOR sur le marché domestique en Côte d'Ivoire (Atyi et al., 2016).

\subsection{Limites de l'étude}

Une contrainte principale a marqué le déroulement de cette recherche. Elle a été conduite dans un contexte peu favorable sur le plan politique. La phase de collecte des données a démarré peu de temps après la tenue des élections législatives, régionales et municipales et avant l'entrée en fonction de plusieurs organes exécutifs nouvellement élus, du fait de contentieux postélectoraux. Cette conjoncture particulière a dans une certaine mesure limité la collaboration des organes techniques. Des suspicions sur les motivations réelles de l'étude ont pu influencer négativement la communication des informations nécessaires à la bonne réalisation de létude. Une autre contrainte a été la configuration du système de marchés publics. Les cellules de marchés publics sont compétentes pour des marchés à partir du seuil de 100 millions de francs XOF ce qui complique l'analyse des marchés de montants inférieurs. Or, les marchés publics inférieurs à 100 millions de XOF constituent une part importante de la commande publique en biens meubles. Ce type de marchés qui concerne une bonne part du mobilier des administrations centrales est fragmenté entre différents départements au sein des ministères rendant difficile l'accès aux informations. Les analyses risquent donc de sous-estimer les besoins en bois pour les marchés publics. 


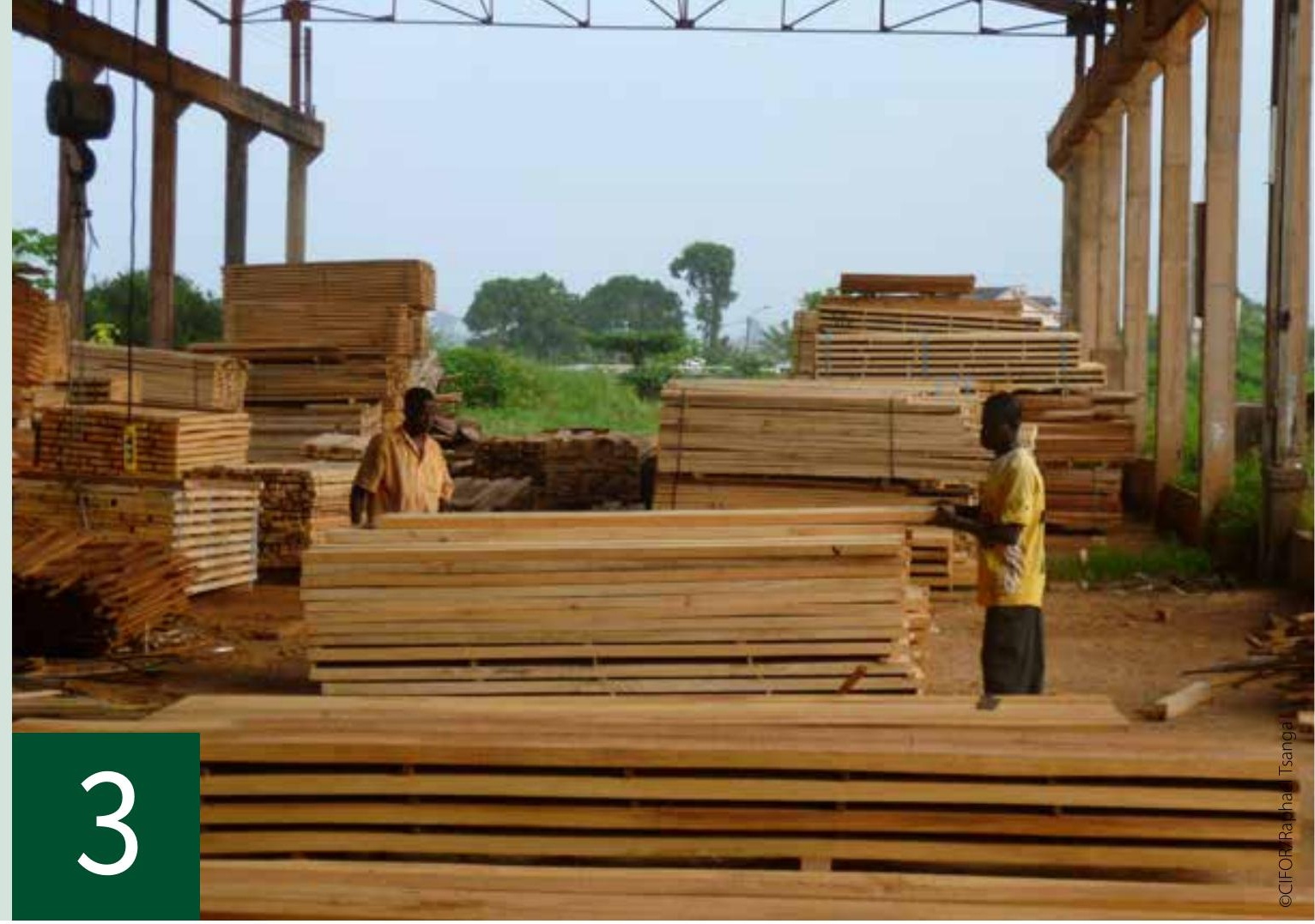

\section{Résultats}

\subsection{Analyse juridique de la prise en compte de la légalité et la durabilité des produits forestiers dans les marchés publics}

Le cadre juridique des marchés publics s'applique à l'ensemble des contrats passés par l'État, les collectivités territoriales et les établissements publics. Ces acteurs publics sont assujettis à une obligation générale de protection de l’environnement dans le cadre de leurs activités. La même obligation peut être étendue aux acteurs privés dans l'hypothèse où les marchés passés par ces derniers bénéficient du concours financier ou de la garantie de l'État ou d'une personne morale de droit public. En outre, la progression de la responsabilité sociétale des entreprises (RSE), accentue le rôle des acteurs privés en matière de protection de l'environnement. Il en découle que les autorités publiques et les acteurs privés agissant pour le compte de cellesci sont théoriquement en première ligne pour agir en faveur de la sauvegarde des forêts notamment dans le cadre des marchés publics. 
La procédure délaboration des marchés publics est soumise à plusieurs principes fondamentaux. L'exigence de transparence y occupe une place particulière dans la mesure. Le recours aux mécanismes de transparence vise à garantir la libre concurrence, l'impartialité et l'intégrité du processus de passation des marchés publics. L'intérêt de la Côte d'Ivoire pour un statut d'observateur à l'Accord sur les Marchés Publics (AMP) consolide cette orientation vers plus de transparence dans les marchés publics (OMC, 2017). D’autres principes gouvernent la politique des marchés publics. C'est notamment le cas du libre accès à la commande publique, de la non-discrimination ou encore l'équilibre économique et financier des marchés publics ${ }^{1}$. Outre ces principes déjà présents dans l'ancien code des marchés publics ${ }^{2}$, l'ordonnance $\mathrm{n}^{\circ} 2019-679$ du 24 juillet 2019 consacre pour la première fois le respect des préoccupations environnementales dans le processus de passation des marchés publics. Ce faisant, le nouveau code des marchés entérine le principe de consommation et de production durables consacré quelques années plutôt par la loi d’orientation du développement durable.

\subsubsection{La consécration normative de la consommation responsable dans les marchés publics}

L'engagement en faveur des marchés publics respectueux de l’environnement est une tendance majeure sur le plan international. Le rôle crucial des marchés publics dans la protection de l'environnement émerge de l'objectif de développement durable (ODD) relatif aux modes de production et de consommation responsables. Cet ODD a pour ambition de favoriser le développement des pratiques durables dans les marchés publics conformément aux politiques nationales. La Côte d'Ivoire a adhéré à la dynamique internationale en consacrant les modes de production et de consommation responsables parmi les piliers de sa politique environnementale. La loi d'orientation sur le développement durable et l'ordonnance $\mathrm{n}^{\circ}$ 2019-679 du 24 juillet 2019 portant code des marchés publics sont les deux principaux textes juridiques matérialisant la prise en compte de la dimension environnementale dans la politique nationale des marchés publics. Ces textes juridiques ne font pas explicitement référence à l'exigence de légalité du bois utilisé dans les marchés publics. Toutefois, la formulation large de leurs dispositions et les concepts utilisés autorisent la prise en compte des critères de légalité et de durabilité dans lélaboration des contrats publics.

La loi d’orientation sur le développement durable pose un cadre général favorable à la prise en compte de la légalité ou la durabilité des produits forestiers dans les marchés publics. Larticle 5 (14) de ce texte affirme que "Les acteurs du développement durable apportent des changements aux modes de production et de consommation en vue de les rendre plus viables et plus responsables sur les plans social et environnemental" ${ }^{\text {. }}$. Cet article doit être lu conjointement avec l'article 13 qui oblige les ministères et les organismes sous leur tutelle à se doter des plans de développement durable ainsi que l'article 14 qui stipule que l'État favorise la responsabilité sociétale des organisations. Ces articles posent les fondements de la commande publique dans une perspective de développement durable. Lobjectif de la consommation durable est articulé autour de l'idée de marchés publics qui mettent l'accent sur l'acquisition des produits respectueux de l'environnement. La consommation durable

1 Ordonnance $\mathrm{n}^{\circ} 2019-679$ du 24 juillet 2019 portant code des marchés publics, art. 8 .

2 Voy. Décret n 2009-259 du 06 Août 2009 portant code des marchés publics, art. 9.

3 Loi n 2014-390 du 20 juin 2014 d'orientation sur le développement durable. 


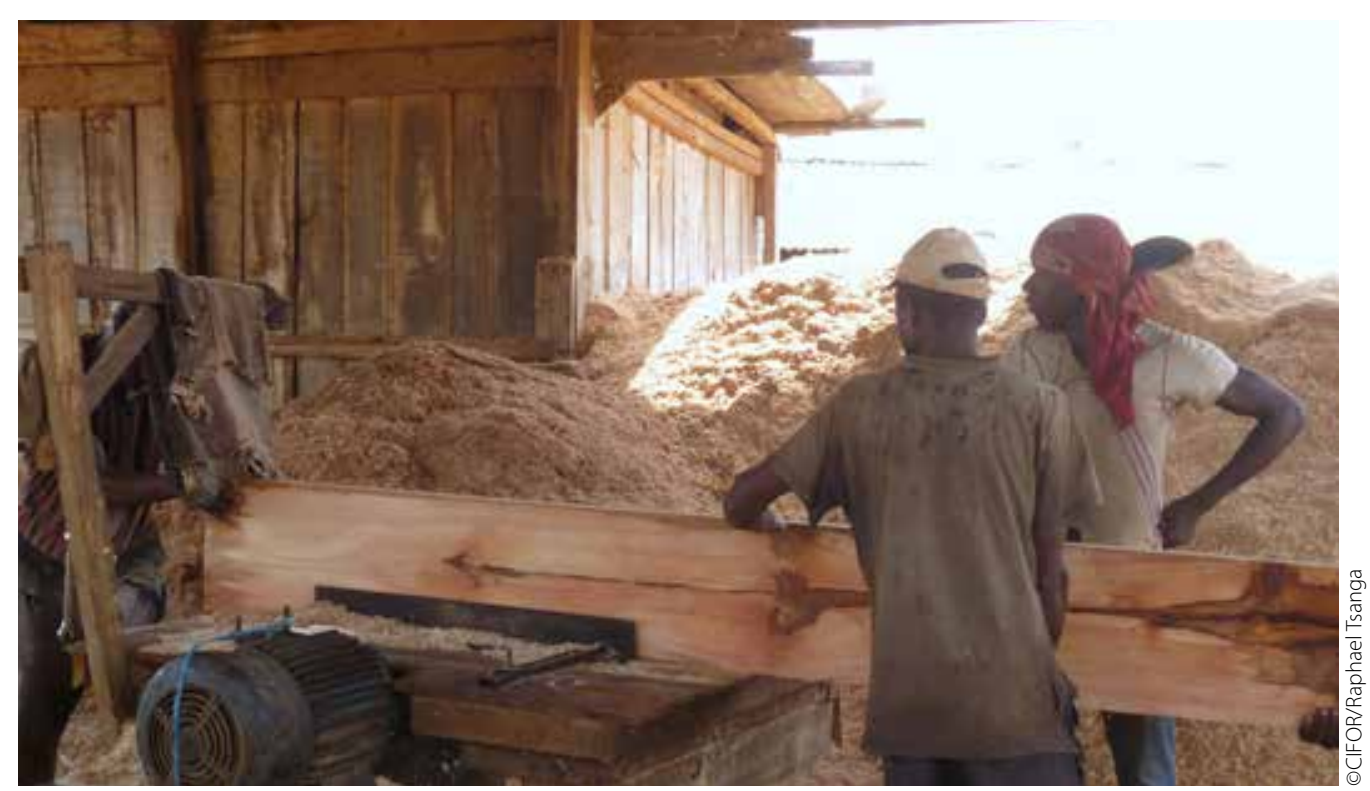

Délignage des rebuts de scierie dans un atelier

est aussi fondée sur une obligation de comportement responsable qui s’applique à tous les acteurs publics dans leurs activités. L’obligation de responsabilité implique un devoir de vigilance et de vérification de la légalité ou la durabilité des chaînes d’approvisionnement des produits avant leur acquisition. Les dispositions de la loi d'orientation ne font pas expressément référence aux bois ou aux produits forestiers et encore moins à leur légalité. Mais le champ relativement large des produits couverts par les marchés publics permet facilement d'y intégrer les préoccupations de légalité et de durabilité du bois et des produits forestiers. L'exigence de consommation responsable exige par conséquent que les maitres d’ouvrage prennent des mesures appropriées pour garantir que la production des produits forestiers se fait dans le respect des lois nationales et que les marchés publics n’absorbent pas de produits d'origine illégale. Cette obligation de vigilance s'applique aussi aux collectivités territoriales. Les dispositions de l'article 32 de la loi d'orientation recommandent en effet à ces entités de veiller à l'intégration des principes et des objectifs de développement durable dans leur fonctionnement et la mise en œuvre de leurs activités ${ }^{4}$. Les dispositions de la loi d'orientation ont été transférées aux marchés publics au regard des évolutions récentes de la législation sur les marchés publics en Côte d'Ivoire.

Lordonnance $\mathrm{n}^{\circ} 2019-679$ du 24 juillet 2019 portant code des marchés publics apporte deux innovations majeures potentiellement utiles pour la prise en compte de la légalité et la durabilité des produits forestiers dans les marchés publics. La première innovation provient des dispositions de l'article 8 qui mentionne l'exigence de respect de la réglementation en matière environnementale, sociale et du travail parmi les principes fondamentaux des marchés publics. Ce principe met expressément en exergue la prise en compte de la

4 Loi n 2014-390 du 20 juin 2014 d’orientation sur le développement durable. 
dimension environnementale et sociale et de protection des travailleurs dans les marchés publics. Ces trois aspects quon retrouve dans les schémas classiques de définition de la légalité des produits forestiers dans le cadre des APV ouvrent des perspectives favorables à une meilleure intégration de la légalité des produits forestiers dans les marchés publics. L'insertion de ce principe dans l'ordonnance de 2019 vient renforcer les actes réglementaires qui autorisaient indirectement la prise en compte des considérations environnementales et sociales dans lélaboration, l'attribution et l'exécution de certains marchés publics. C'est notamment le cas du décret $\mathrm{n}^{\circ} 2015-475$ du 1er juillet 2015 qui assujettit conjointement la passation des marchés faisant l'objet de cofinancement aux dispositions du code des marchés publics et aux directives du partenaire technique et financier. Ainsi, dans le cadre de projets spécifiques, la mobilisation des procédures des partenaires techniques et financiers peut de manière incidente favoriser la prise en compte des préoccupations liées à la durabilité.

La seconde innovation porte sur l'intégration de la notion d'achat durable dans le cadre juridique. Selon l'article $1^{\text {er }}$, la notion d'achat durable renvoie aux acquisitions des autorités publiques qui intègrent les objectifs de développement durable dans la définition des besoins, leur nature ainsi que leur étendue. La référence aux achats durables intervient à différentes phases de la procédure de passation des marchés publics. Dans la phase préparatoire, l'exigence d'achat durable doit être prise en compte dans la définition des besoins de l'autorité contractante. Larticle 19 précise à ce sujet que les besoins des autorités contractantes sont déterminés en fonction des principes, spécifications et contraintes de l'achat durable. Pour ce qui est de la constitution du dossier d'appels d'offres, l'article 22 affirme que celui-ci doit comporter des exigences applicables en matière d'achat durable et de responsabilité sociale des entreprises, en plus des clauses administratives, juridiques, financières et techniques habituelles. S’agissant enfin des documents constitutifs du marché, l'article 25 institue un cahier de clauses environnementales et sociales ou tout autre cahier élaboré en conformité avec les obligations de l'autorité contractante liées au respect des principes de l'achat durable. Ce dernier point est particulièrement intéressant pour la légalisation des bois utilisés dans les marchés publics. Lélargissement de la typologie des cahiers des charges laisse la possibilité au maître d'ouvrage de fixer des exigences portant sur la légalité lorsque le marché porte sur l'acquisition de biens à base de bois ou la réalisation des infrastructures nécessitant l'utilisation du bois.

Le cadre normatif ainsi posé est clairement favorable à la prise en compte de la légalité du bois dans les marchés publics de biens ou de construction des infrastructures. Les possibilités offertes par les textes juridiques restent cependant théoriques pour plusieurs raisons.

Premièrement, l'entrée de la notion d'achat durable dans le champ juridique est relativement récente, ce qui fait que son intégration dans les processus de passation des marchés publics demande encore à être consolidée. En clair, la prise en compte des considérations environnementales dans la formulation des cahiers des charges ou dans l'attribution des marchés nest pas encore effective. Deuxièmement, les orientations fixées par le code des marchés publics doivent encore être complétées par des textes d'application. Ceux-ci devraient préciser les critères à insérer dans les cahiers des charges pour garantir la légalité du bois utilisé dans les marchés publics. Troisièmement, le code des marchés publics reste muet sur l'éventualité d'une préférence en faveur des contractants respectueux de l'environnement ou engagés dans des démarches de responsabilité sociétale et environnementale. Autrement dit, le code ne fournit aucune indication sur la question de savoir si l'insertion des critères 
environnementaux dans une offre peut jouer un rôle décisif dans l'attribution des marchés. Tous ces éléments suggèrent que les principes de consommation durable nont pas encore imprégné les appareils administratifs, de même que le rôle de levier que pourraient jouer les marchés publics dans la protection de l'environnement.

\subsubsection{L'application difficile de l'exigence de légalité des produits forestiers dans les marchés publics de l'État et des bailleurs de fonds internationaux}

Les approvisionnements de l'État et de ses démembrements territoriaux ou techniques s'appuient sur les textes juridiques en vigueur. Comme le montrent les analyses du corpus juridique relatives aux marchés publics, l'origine du bois utilisé dans les chantiers publics est une question accessoire. En conséquence, pour les acteurs publics, la légalité du bois nest pas un impératif dans la procédure de passation et d'exécution des marchés publics.

En l'état actuel, l'environnement et la pratique des acteurs publics en Côte d'Ivoire indiquent qu'il n'existe pas de stratégie formelle ou informelle incitant à l'utilisation de bois et produits forestiers de source légale dans la commande publique. Les approvisionnements en biens divers et la réalisation des infrastructures sont guidés pour l'essentiel par le rapport qualitécoût. Cette logique de recherche de la meilleure prestation au coût le moins élevé ou tout au moins le plus avantageux est partagée par les services centraux de l'État et les collectivités territoriales décentralisées. De fait, la donnée la plus importante concerne la bonne exécution technique des marchés et leur livraison dans les délais contractuellement arrêtés. Dans ces conditions, aucune importance n'est accordée à l'origine du bois utilisé dans la réalisation des chantiers de construction ou la fabrication des meubles commandés par les collectivités publiques.

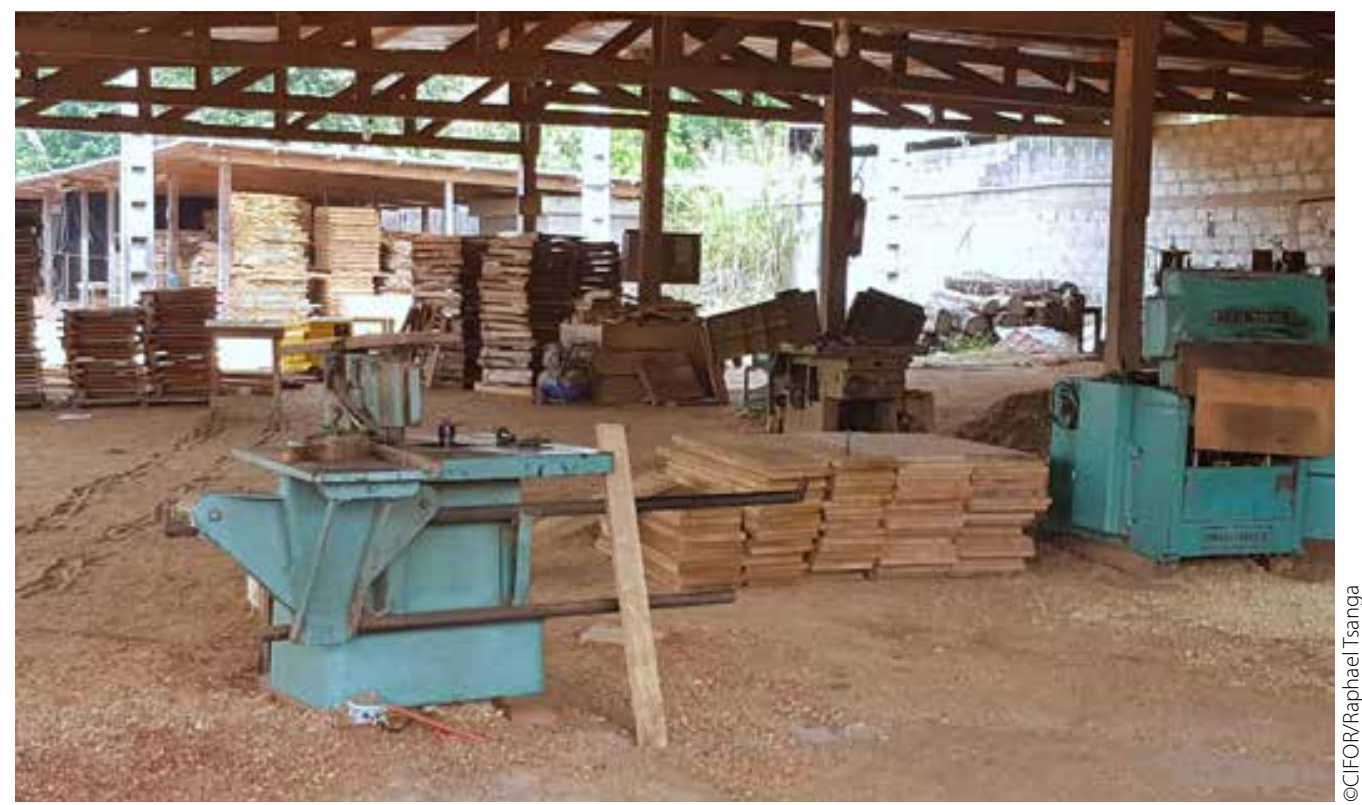


Au niveau central comme au niveau local, les acteurs s'accordent à mettre en avant les dispositions du code des marchés et des réglementations subséquentes, lesquelles ne font aucune référence à l’origine de la ressource. À travers les clauses techniques, le dossier d'appel d'offres recommande aux maîtres d’ouvrage de détailler les caractéristiques du produit, bien que lesdites caractéristiques techniques concernent le produit au sens strict sans sétendre à l'origine de la matière première nécessaire à la fabrication du produit. Ainsi, les dossiers d'appel d’offres mentionnent très souvent le type d'essence à utiliser, notamment dans le cas des chantiers de construction. Les références à la matière première se déclinent essentiellement sous la forme de suggestions d'une liste d'essence de bois parmi lesquelles le prestataire devrait sélectionner celle qui est la mieux adaptée à la réalisation de la commande publique. Il s'agit de spécifications de nature générale qui n'imposent pas d’obligations particulières aux prestataires quant à la connaissance de l'origine ou à la légalité des produits concernés.

Concernant les partenaires techniques et financiers, leur faible participation à l'étude a rendu difficile l'accès à leurs stratégies d’approvisionnement ainsi que la vérification de l'effectivité de ces stratégies. Les discussions avec la Banque mondiale (BM) ont établi que la sauvegarde des écosystèmes forestiers est une préoccupation constante dans les opérations financées par cette institution. Elle dispose à cet égard d'un cadre environnemental et social auquel doivent se conformer les pays emprunteurs. Sa politique dans le cadre du financement des projets requiert ainsi la conformité à une dizaine de normes environnementales et sociales relatives entre autres à la préservation de la biodiversité et la gestion durable des ressources naturelles biologiques, l'utilisation rationnelle des ressources naturelles, ou la prise en compte des populations autochtones (Banque mondiale, 2017). S’agissant spécifiquement de la politique opérationnelle relative aux forêts, celle-ci stipule que la Banque mondiale ne finance pas des projets ni directement de plantations ayant pour effet la conversion ou une dégradation significative des forêts et autres habitats critiques, de même que le financement d’opérations de récolte de bois à but commercial n'est possible qu'après vérification du caractère responsable de lopération attestée par un système de certification forestière indépendant (Banque mondiale, 2002).

L'AFD dispose d'une politique similaire dans le cadre du financement des projets d'infrastructures, s'assignant une obligation de diligence raisonnée indispensable à la conformité des projets aux exigences environnementales et sociales (AFD, 2016). À l'analyse, ces politiques se déclinent au niveau opérationnel sous la forme études d'impact environnemental (EIE). Pour pertinentes quelles soient, les EIE ont un champ d'intervention et des objectifs spécifiques. Elles sont davantage tournées vers la correction ou l'atténuation des impacts dans l'environnement, et ne considèrent pas directement les questions liées à l'origine des matériaux utilisés dans la réalisation des infrastructures. De même, l'existence au plan interne des politiques formelles obligeant les prestataires à s'approvisionner en bois légal n'a pas été portée à notre attention.

À la question de savoir si la mise en place d'une politique d'achat responsable de bois est une démarche réaliste, tous les acteurs soulignent l'utilité, voire la nécessité d'une telle démarche. De l'avis des autorités de régulation par exemple, il serait "simple" d'insérer une clause obligeant les co-contractants de l'État à s'approvisionner auprès de sources autorisées. Toutefois, une telle évolution devrait prendre en compte des éléments tels que l'applicabilité de la mesure et son impact potentiel sur les coûts des marchés. Des bois conformes aux exigences légales risquent en effet d'avoir des prix de revient supérieurs à ceux des bois issus de filières informelles. 


\subsubsection{La restriction de la légalité des produits forestiers à la législation sectorielle}

La question de la légalité est aujourd'hui efficacement prise en compte par la nouvelle loi forestière de 2019 et par ses textes d'application en cours d'adoption, mais elle n'est pas abordée de manière pratique et opérationnelle quand l'État doit lui-même s'impliquer comme acteur dans le marché du bois. Les questions de légalité des produits forestiers demeurent confinées dans le cadre juridique sectoriel (droit forestier et réglementations sectorielles), sans être déclinées dans l’ensemble des politiques et des pratiques publiques.

La légalité du bois est une préoccupation constante pour le législateur en matière forestière. Elle se traduit autant dans l'encadrement de l'exploitation forestière et la transformation des débités, que dans celui de l'utilisation et la commercialisation du bois d'œuvre où l'insertion d'une exigence de produits d'origine légale suppose que la demande dispose d'espaces ou de lieux où trouver de tels produits.

Indirectement et sans lien avec une quelconque idée de marchés publics écologiques, la question de la légalité du bois circulant sur le marché domestique avait été prise en considération par l'arrêté $\mathrm{n}^{\circ} 624 \mathrm{du} 24$ novembre 2011 portant identification de l'origine légale et traçabilité des produits forestiers commercialisés en Côte d'Ivoire. Ce texte avait pour objectif d'amener les vendeurs de bois d'œuvre, les menuisiers et les ébénistes, à commercialiser ou utiliser du bois provenant de sources légales. À cet effet, l'arrêté avait institué un agrément permettant de vérifier l'origine légale des produits forestiers commercialisés sur l'ensemble du territoire national, ainsi qu'un registre mentionnant les sources et modes d'approvisionnement. Les outils mis en place jusqu'ici pour garantir

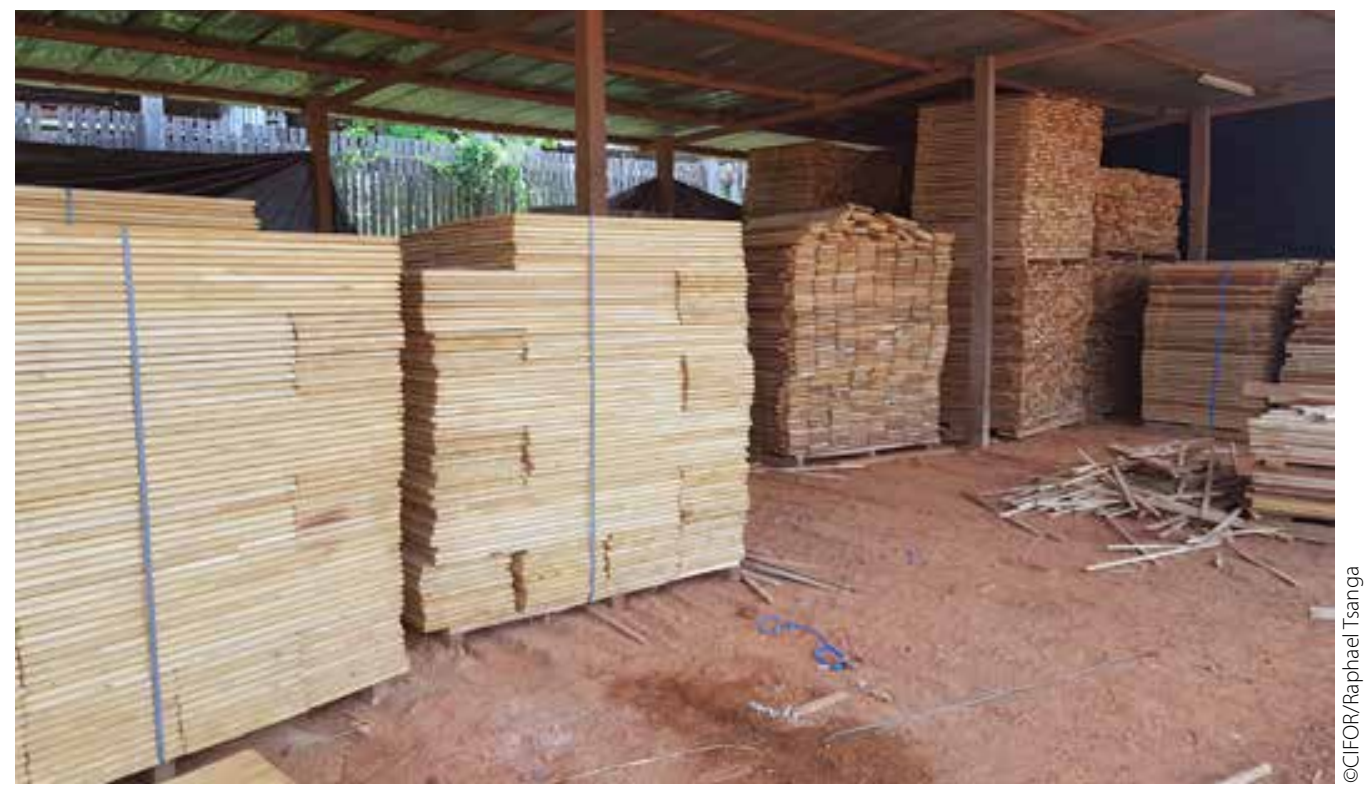

Produits destinés à la fabrication de meubles pour marché local 
la légalité du bois commercialisé sur le marché domestique ne semblent cependant pas avoir produit les effets escomptés, qu'il s'agisse du recensement des entrepôts ou du suivi des approvisionnements. Bien au contraire, le confinement involontaire de l'exigence de légalité des produits forestiers à la réglementation liée à l’offre n'incite pas le consommateur en général et surtout le consommateur public à intégrer cette exigence dans ses habitudes de consommation. Il en découle une rupture, voire une tension entre d'une part les préoccupations de légalité et parfois de durabilité, qui demeurent exclusivement des considérations sectorielles, et d'autre part les principes fondamentaux des marchés publics, qui eux sont encore majoritairement gouvernés par les exigences d'efficacité et d'économie des ressources publiques, mais sans considération pour la légalité et la durabilité.

\subsection{Consommation de sciages et de meubles en bois par les marchés publics}

\subsubsection{Estimation du volume de sciages utilisés dans les marchés publics}

Au niveau de l'État central, la consommation de sciages se fait essentiellement dans le cadre des chantiers de réhabilitation des infrastructures, lesquels représentent 66 pour cent des marchés passés par les départements ministériels. Le reste, soit 34 pour cent, concerne la construction de bâtiments pour les services publics. La réhabilitation des infrastructures dont la dégradation est sans doute liée en grande partie à la crise du début de la décennie 2010 est une opération qui mobilise quasiment tous les départements ministériels, et qui requiert notamment l'utilisation d'importantes ressources forestières en sciages et en produits bois. Au niveau des collectivités, les résultats montrent que les marchés concernent plutôt les travaux de construction (73 pour cent) avec comme axe prioritaire, les investissements dans le secteur de léducation, suivi de la santé. Au total, les marchés de construction et de réhabilitation des infrastructures diverses représentent 98 pour cent de la consommation de sciages par les collectivités locales.

Sans surprise, les administrations centrales passent les marchés les plus importants en volume même si leur nombre est plus réduit (figure 3.1). À l’inverse, les collectivités locales totalisent un plus grand nombre de marchés publics mais avec des niveaux de consommation de sciages moins importants (figure 3.2).

Sur la base de la documentation disponible, la consommation de sciages pour les marchés de construction ou de réhabilitation des infrastructures publiques (établissements scolaires, formations sanitaires, bâtiments administratifs) et la fabrication de mobilier scolaire est de $113572 \mathrm{~m}^{3}$ de sciages. Cette consommation en apparence faible est probablement sous-estimée si l'on considère des paramètres tels que la croissance économique et ses implications en termes de mise à niveau et de réalisation de nouvelles infrastructures. 


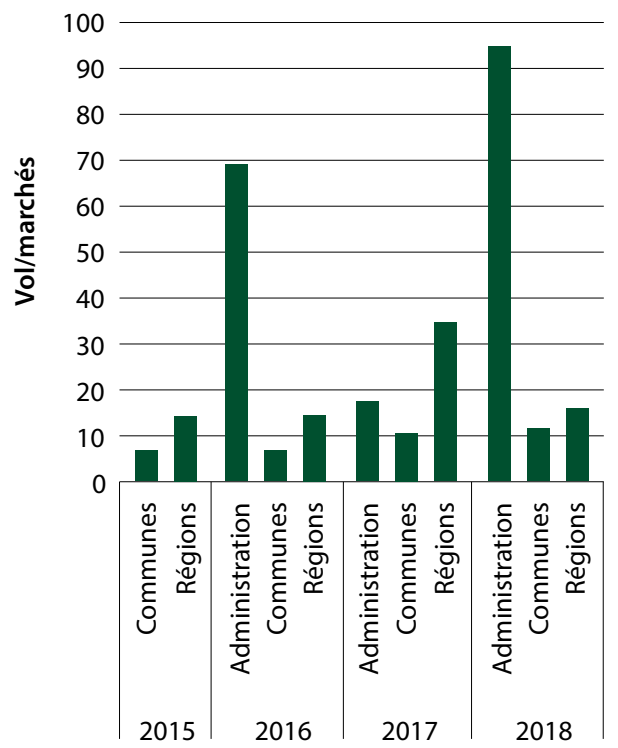

Figure 3.1 Volumes moyens / marchés

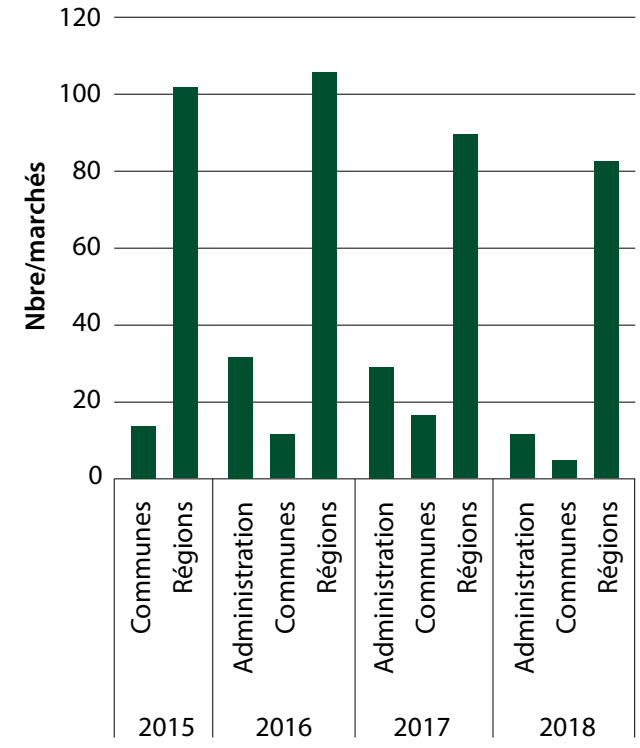

Figure 3.2 Nombre moyen de marchés par entité

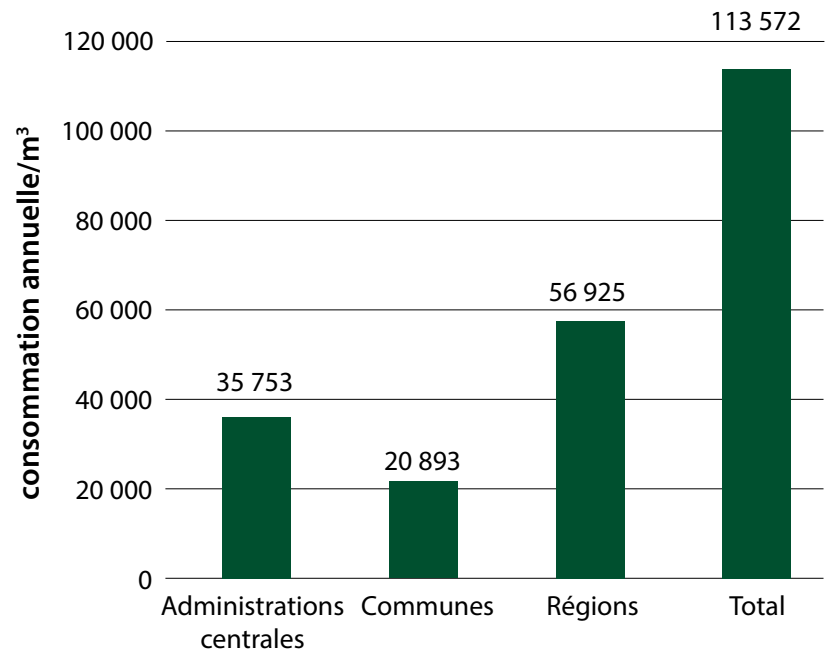

Figure 3.3 Consommation annuelle de sciages 


\subsubsection{Acquisition des meubles}

Le marché du meuble est dans une dynamique de forte expansion depuis le milieu des années 2000 avec une certaine accélération au cours des cinq dernières années. De 2007 à 2018, la progression des importations de meubles a quasiment été multipliée par quatre, passant de 7 à 27 milliards de XOF en l'espace de 10 ans (figure 3.4). Les meubles en bois et produits dérivés représentent une part relativement importante de ces importations avec une valeur de près de 12 milliards de XOF en 2018, malgré un léger fléchissement en 2017. Selon toute vraisemblance cette tendance est amenée à se poursuivre dans les prochaines années.

De la même manière que les acteurs ne cherchent pas à attester la légalité de la ressource utilisée pour les meubles produits localement, les meubles d'importation jouissent d'une présomption de légalité. Bien qu’elle soit discutable dans l’absolu, elle témoigne de la complexité, sinon de l'impossibilité d'une vérification de l’origine légale des produits. La légalité de la source d’approvisionnement semble de plus en plus difficile à attester au fil des différentes étapes de la transformation. Le contrôle de légalité des divers mobiliers acquis par l'État et les collectivités publiques locales est inexistant. Or, de manière empirique, la préférence des autorités publiques va vers le mobilier d'importation. Cette catégorie de meubles présente les caractéristiques de standardisation, de disponibilité immédiate ou rapide à la commande, de stabilité et de confort apparent, qui semblent décisifs dans le choix des autorités. Cette tendance avait déjà été observée dans le contexte camerounais où la demande privée s'est avérée sensible aux mêmes critères (Lescuyer et al., 2016).

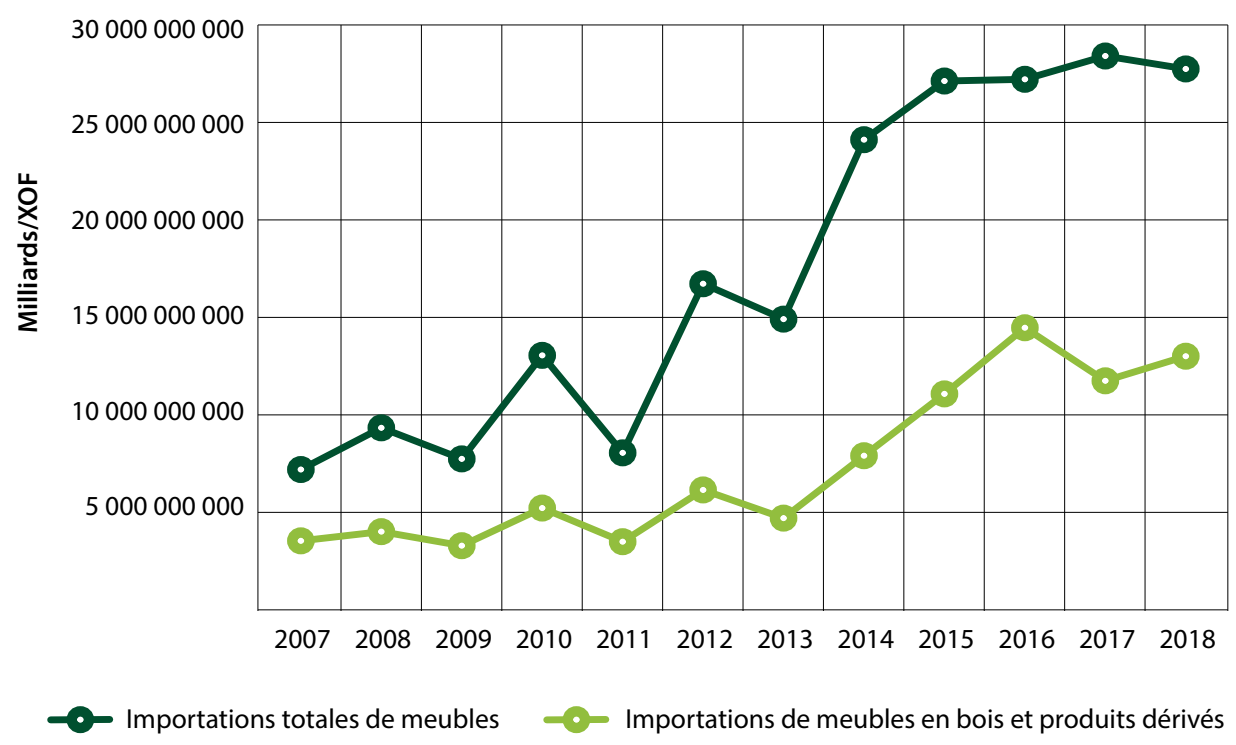

Figure 3.4 Importations de meubles en Côte d'Ivoire

Source: INS 


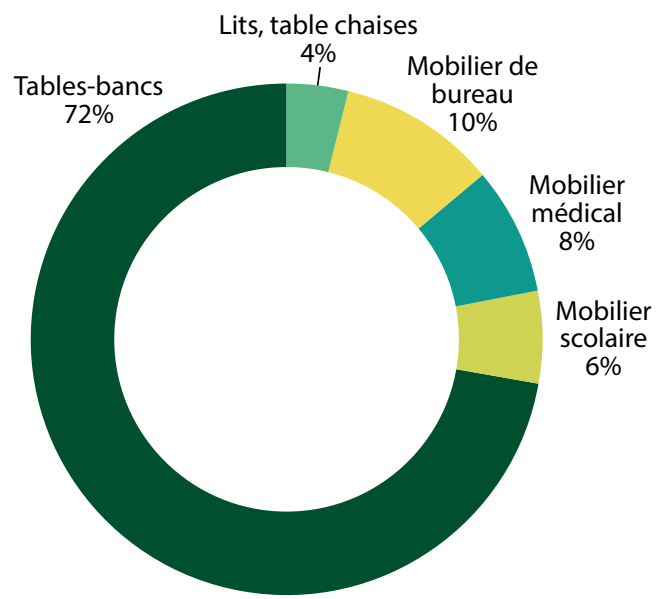

Figure 3.5 Typologie des achats publics de mobiliers

La question des importations de meubles est intimement liée à la question du type de produits que recherchent majoritairement l'État et les collectivités locales. En termes de caractéristiques, les achats publics de meubles sont essentiellement portés vers du mobilier de bureau, les tables-bancs et accessoirement vers d'autres types de produits tels que tables, chaises et autres. Sur le plan quantitatif cependant, le processus d'acquisition de ce type de produits rend l'analyse de leur importance financière complexe. Le processus d'acquisition du mobilier de bureau est relativement atomisé du fait du partage de compétence entre plusieurs directions. Les achats ne sont pas réalisés de manière groupée pour tous les services de l'État, mais par chaque institution, voire même individuellement par chaque entité constitutive d'une même institution publique. Cette fragmentation rend quasi impossible une quantification exhaustive de l'ensemble des acquisitions.

Dans cet ensemble hétérogène, les tables-bancs occupent une place toute particulière. C'est en effet un des principaux postes de dépenses de l'État et des collectivités locales en matière d'acquisition de biens et services auquel s'ajoute l'apport des partenaires techniques et financiers. Pour la période de 2016 à 2018, le mobilier scolaire et plus particulièrement les tables-bancs, 119573 tables-bancs ont été acquis par l'État et les collectivités locales pour environ 7,1 milliards XOF. Le mobilier scolaire combine à la fois des produits d'importation et des produits fabriqués localement. De ce point de vue, il existe une concurrence entre ces deux types de mobilier. Le marché du table-banc constitue donc un important levier potentiel d'incitation à la légalité au regard des montants financiers en jeu. Rien que pour l'année 2018-2019, la demande en table-bancs pour l’enseignement général, technique et professionnel est estimée à 517550 unités. C’est donc un levier stratégique dont la mobilisation risque cependant de renforcer la position de certains industriels déjà positionnés sur ce segment, et d'exclure de manière définitive les artisans-menuisiers qui peinent à pénétrer ce marché. 


\subsection{Production des meubles dans les entreprises artisanales de bois}

\subsubsection{Caractéristiques des menuiseries artisanales}

La notion d'entreprise artisanale est envisagée ici telle que définie par la loi de 2014 régissant l'artisanat en Côte d'Ivoire. Rentrent dans cette catégorie, les entreprises individuelles ou familiales, les sociétés civiles professionnelles, les coopératives, les groupements d'intérêt économique et les sociétés à responsabilité limitée du secteur de l'artisanat qui emploient moins de 200 individus de manière permanente. Qu'elles soient de nature collective ou individuelle, les entreprises artisanales sont soumises à l'obligation d'immatriculation et d'agrément. Sur les 324 entreprises artisanales visitées, très peu disposent d'un agrément tel que prescrit par la loi. La suspension du contrôle des agréments des unités de menuiseries et débénisterie explique en partie ce faible nombre d'opérateurs agréés. D’autres explications plausibles sont le coût de l'agrément et la fiscalité afférente à la formalisation d'une entreprise de menuiserie. L'installation des premières unités de menuiserie remonte à la fin de la décennie 1960 (figure 3.6). Depuis cette période, le nombre de nouveaux ateliers n’a cessé de progresser avec une forme de stabilisation au cours des cinq dernières années. Le relatif dynamisme de la filière ne doit pas occulter une certaine instabilité. Les sites occupés par les opérateurs sont pour la plupart occupés de manière temporaire avec des risques réels de déguerpissements par les autorités publiques.

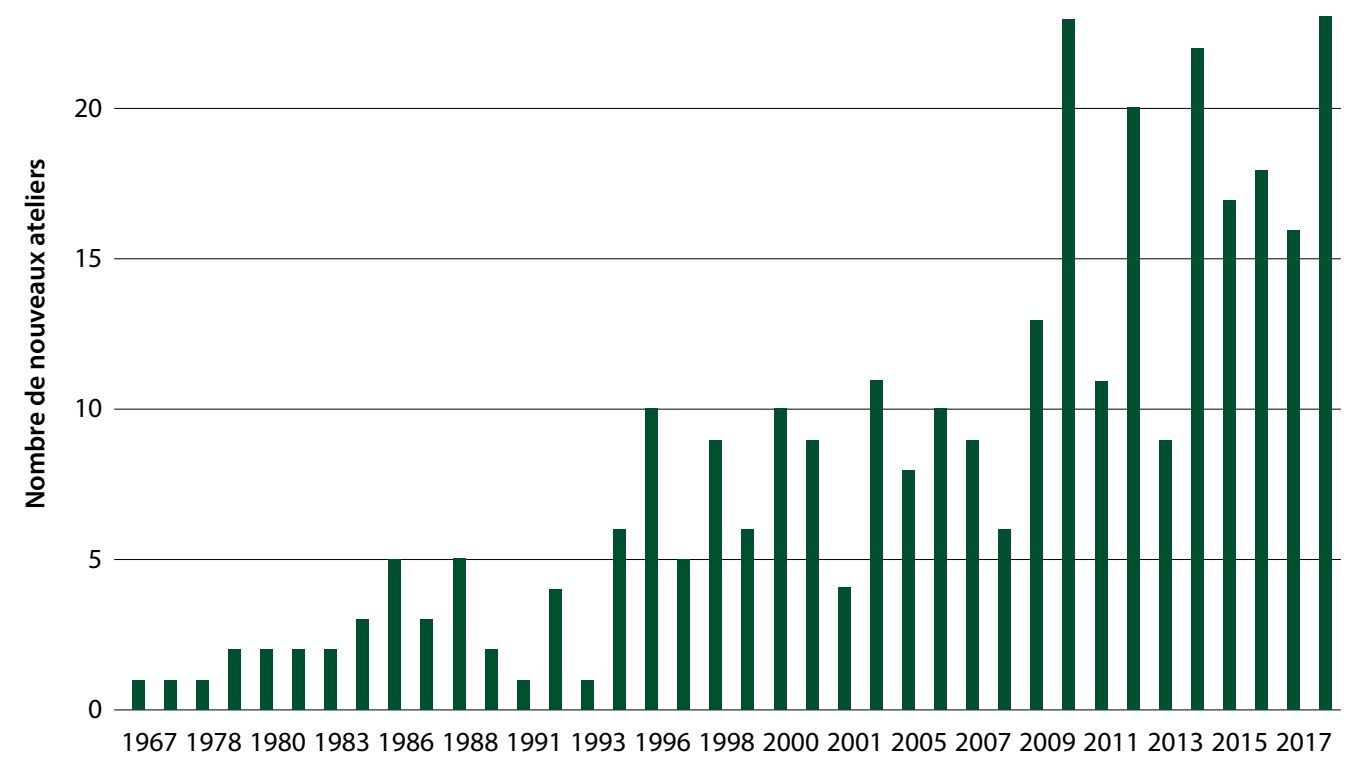

Figure 3.6 Création de nouveaux ateliers 
Les ateliers de menuiserie et d'ébénisterie visités regroupent une multitude de corps de métiers et de spécialités (figures 3.7 et 3.8) et emploient 1242 personnes dont 93 pour cent de manière permanente, soit une moyenne de 3,9 employés par menuiserie. Il y a une forme d'attractivité pour cette activité au regard du nombre d'individus qui se mettent à l'apprentissage. En revanche, les emplois très spécialisés comme les vernisseurs, les tapissiers et les ébénistes comptent parmi les plus faibles en proportion et sont les plus importants dans la catégorie non-permanent. L’explication se trouve dans la qualification élevée des acteurs qui exercent ces métiers, d'où leur sollicitation sur des bases ponctuelles.

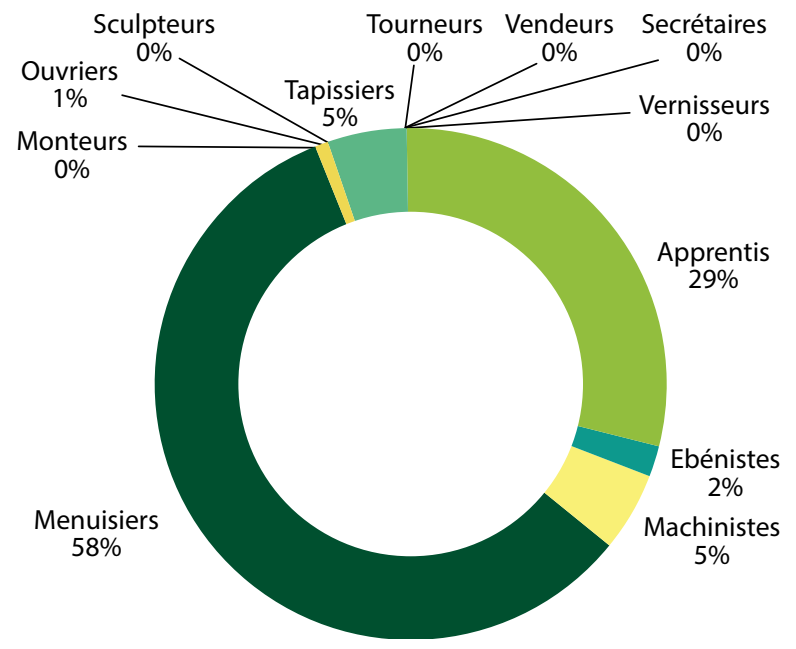

Figure 3.7 Type de métiers dans les menuiseries

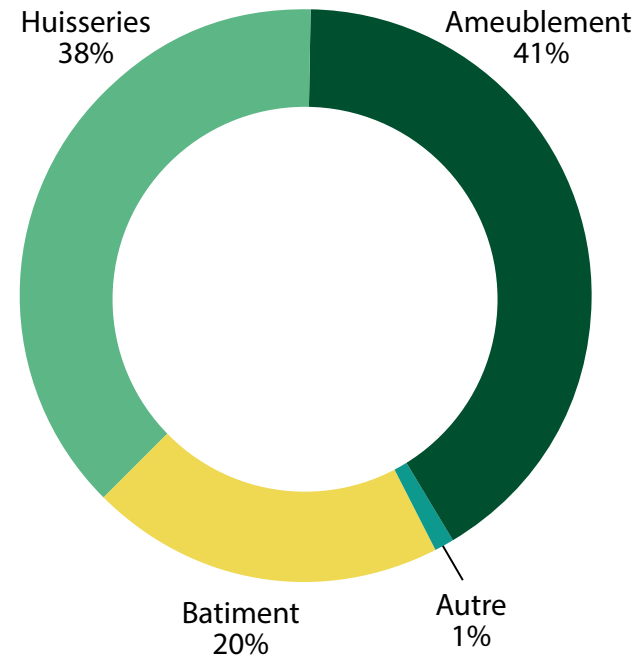

Figure 3.8 Spécialisation des menuiseries

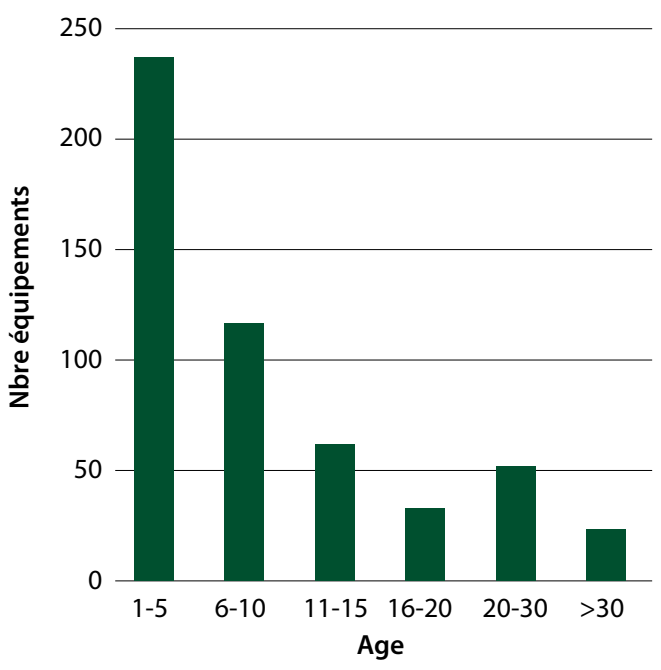

Figure 3.9 Âge des équipements 
La majorité des opérateurs est de nationalité ivoirienne (84 pour cent), ce qui distingue ce secteur du segment de la vente largement dominé par des ressortissants dits Haoussas très souvent d’origine nigérienne ( 69 pour cent) et malienne ( 31 pour cent).

Pour ce qui est des équipements, le matériel utilisé est constitué en majorité de produits d’occasion (72 pour cent) ayant été utilisés pendant 8 ans en moyenne par leurs détenteurs actuels en Côte d'Ivoire. Même si la date moyenne d'acquisition est donc assez récente pour la plupart des équipements, les observations in situ montrent que les équipements utilisés sont souvent très anciens.

Nombre de ces équipements sont dédiés aux travaux de finitions, ce qui signifie qu'une part importante de l'activité est exécutée en dehors de la menuiserie. Cela illustre également les contraintes financières que rencontrent les unités de menuiserie pour se doter en équipements performants qui leur permettraient d'avoir des chaînes de production suffisamment intégrées. En dépit des contraintes liées à l'acquisition des équipements de dernières générations, certains opérateurs de la filière ont présenté des produits d'une qualité susceptible de concurrencer les produits importés. Cependant, comme cela a été démontré dans une étude sur le Cameroun, les artisans ivoiriens ont des coûts de facteurs de production relativement élevés, phénomène qui plombe leur compétitivité face aux produits importés.

\subsubsection{Spécificités des produits fabriqués}

Bien que la fabrication des charpentes fasse partie de leur activité, la majorité de la production des menuiseries est la fabrication de meubles (tableau 3.1). Loffre de meubles proposée par les artisans menuisiers ne répond pas dans la plupart des cas aux besoins des autorités publiques, que ce soit du point de vue des spécifications techniques, du niveau de standardisation, ou de la qualité. Plusieurs raisons sont évoquées pour expliquer la qualité médiocre des produits. La première raison tient au séchage du bois. En l'état actuel, l'absence de séchoir dans les sites de production des meubles par les menuisiers impacte négativement leur image, puisque l'absence de stabilité qui en découle fonde en grande partie des acheteurs (qu'ils soient publics ou privés) dans les capacités professionnelles des menuisiers, ou en tout cas dans leur capacité à fournir des produits de qualité.

La deuxième raison tient à la formation des artisans. Les artisans rencontrés soulignent qu'ils n’ont pas les compétences techniques qui leur permettraient d’avoir la maîtrise des outils, techniques et des technologies susceptibles d'améliorer qualitativement leur offre de produits et de gagner en compétitivité. La question de la formation est d'autant plus importante dans un contexte où il existe un décalage entre l'offre de bois disponible - faible, et les techniques de travail des artisans, qui entraînent une consommation importante de matière première (notamment pour le dégauchissage des sciages de bois de brousse et pour le rabotage). La rareté de la ressource exige en effet une mutation radicale des techniques de fabrication qui amènera les artisans à travailler avec du bois de récupération, phénomène encore relativement marginal.

La troisième contrainte est l'accès à une matière première de qualité auprès des industriels. Dans la configuration actuelle, les artisans ne disposent pas des capacités financières nécessaires pour accéder au bois industriel, monopolisé par les négociants haoussas, et relativement onéreux de leur point de vue. Des initiatives de mise en place de centrales d'achats germent pour remédier à ce problème, mais elles restent trop peu concluantes pour être généralisées pour le moment. 
Tableau 3.1 Types de produits

\begin{tabular}{|c|c|c|}
\hline Type de produit & Quantité fabriquée (unités) & Chiffre d'affaires (XOF) \\
\hline Argentiers & 20 & 2800000 \\
\hline Armoires & 26 & 3440000 \\
\hline Autres & 814 & 1707500 \\
\hline Bancs & 150 & 15900000 \\
\hline Bibliothèques & 15 & 3725000 \\
\hline Bureaux & 7 & 1070000 \\
\hline Cadres & 2128 & 57742500 \\
\hline Chaises & 1053 & 5340000 \\
\hline Charpentes & 61 & 1840000 \\
\hline Coiffeuses & 12 & 440000 \\
\hline Dressing & 1 & 1000000 \\
\hline Étagères & 2 & 20000 \\
\hline Fauteuils & 179 & 49340000 \\
\hline Lambris & 51 & 37000 \\
\hline Lits & 572 & 44325000 \\
\hline Meubles de cuisine & 1 & 30000 \\
\hline Meubles de rangement & 4 & 600000 \\
\hline Meubles TV & 3 & 190000 \\
\hline Panneaux de porte & 21 & 1050000 \\
\hline Placards & 552 & 25260001 \\
\hline Portes & 2826 & 86964025 \\
\hline Portes de placards & 24 & 600000 \\
\hline Salles à manger & 19 & 2500000 \\
\hline Salons & 132 & 15390000 \\
\hline Tableaux & 4 & 80000 \\
\hline Tables-bancs & 230 & 361360000 \\
\hline Tables & 273 & 7697000 \\
\hline Total & 9180 & 690448026 \\
\hline
\end{tabular}

Face à ces difficultés, les menuisiers s’approvisionnent sur le marché local en majorité avec des rebuts industriels. Pour la fabrication des meubles, les artisans recourent au bois de brousse (premier choix), mieux adapté à leurs besoins. Une dizaine d'essences sont couramment utilisées, les plus importantes étant le framiré, l'acajou et le fraké.

La légalité du bois utilisé est une préoccupation relativement anecdotique, aussi bien pour les menuisiers que pour leurs clients. La notion de légalité est elle-même mal comprise par ces acteurs. La preuve de légalité la plus souvent évoquée est la qualité du bois, vient ensuite, la référence aux bons de sortie d'usine. Il s'agit de preuves de légalité bien fragiles dans l'ensemble surtout pour ce qui est de la qualité des sciages dont il est par ailleurs établi que plusieurs sont façonnés dans des ateliers clandestins de délignage. 


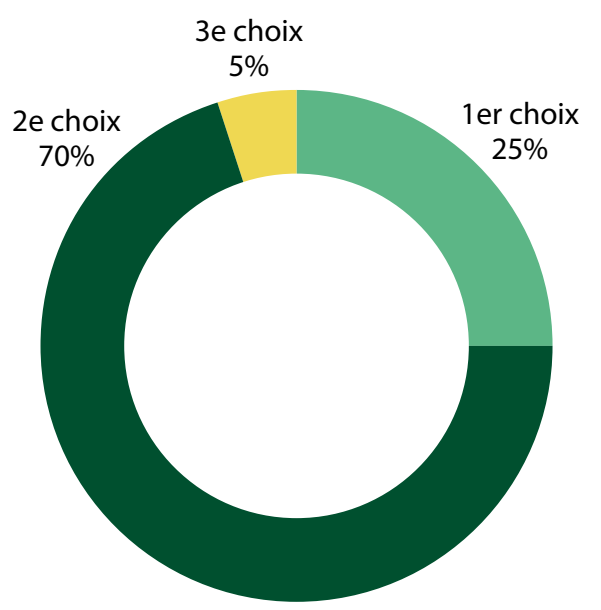

Figure 3.10 Qualité des sciages utilisés

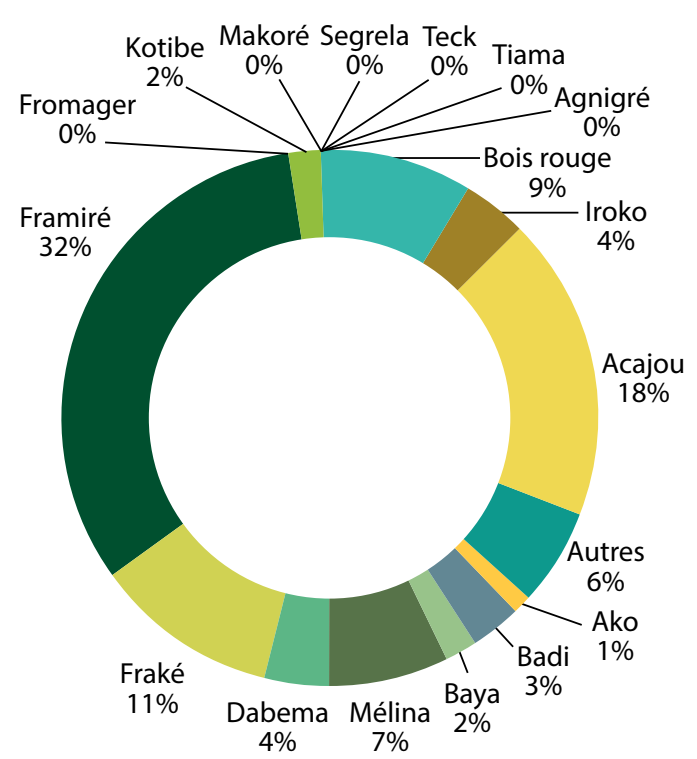

Figure 3.11 Principales essences utilisées

Ces différentes contraintes amènent à la conclusion selon laquelle un très faible nombre d'entreprises artisanales sont en capacité sur le plan technique et financier de répondre aux exigences de la commande publique. Si le cadre juridique réserve, en théorie tout au moins, une portion des marchés publics aux PME nationales, ce qui serait une incitation à la légalité, l’environnement global des marchés publics et de la filière sont autant d'obstacles à un engagement des PME sur ces marchés.

Les entraves liées au financement constituent d'autres goulots d'étranglement importants. Les délais de liquidation de la dette publique compris entre 91 et 180 jours sont évidemment très longs de l'avis des petits opérateurs (Groupe de la Banque mondiale, 2016). Parallèlement, l'accès à la ressource auprès des industriels peut s'avérer problématique au regard du caractère souvent informel de la commercialisation de sciages comme le révélait déjà un rapport il y a quelques années (Finifter, 2010). Il faut enfin signaler les problèmes liés à la non généralisation du paiement de la TVA: vouloir vendre sur un marché légal, cela peut souvent impliquer qu'il faille considérer les pertes financières consécutives à la TVA non recouvrée puisque les Haoussas, principaux vendeurs de bois de brousse $1^{\text {er }}$ choix utilisés par les artisans, privilégient presque systématiquement les paiements en espèces aux paiements par chèque, sans prise en compte de la TVA. 


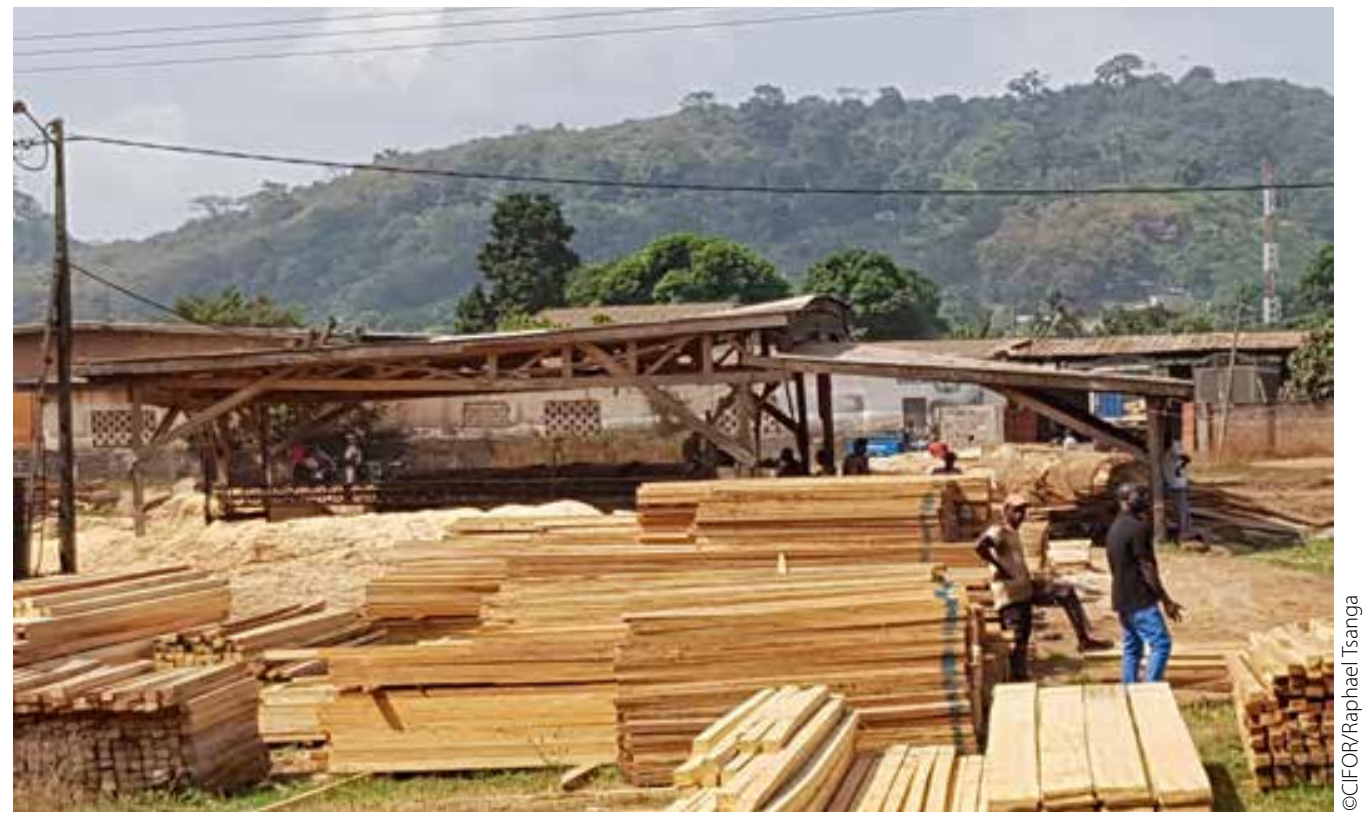

Site de transformation de bois à destination du marché local.

\subsection{Offres de bois légal disponibles sur le marché domestique}

\subsubsection{Les sources d'approvisionnement autorisées}

La provenance du bois consommé localement ou exporté a profondément évolué depuis le code forestier de 1965 (figure 3.12). En 2019, la Côte d'Ivoire a adopté un nouveau code forestier qui met l'accent sur la gestion durable et la gouvernance. La nouvelle législation apporte des changements majeurs dans la configuration des sources de provenance du bois. L'exploitation forestière est désormais autorisée dans quatre espaces, à savoir, les forêts classées (FC) de l'État ou des collectivités territoriales, les agro-forêts, les forêts communautaires et les plantations forestières. Des innovations sont aussi apportées dans les modalités d'exploitation. La concession de gestion constitue le nouveau mode d'exploitation des forêts classées et des agro-forêts, tandis que l'autorisation ou la déclaration constitue le nouveau régime de l'exploitation forestière et des coupes de bois dans le domaine rural ${ }^{5}$. La nouvelle législation consacre la disparition des périmètres d'exploitation forestière (PEF) institués en $1994^{6}$ et qui constituaient la principale source de provenance du bois en Côte d'Ivoire. Les PEF restent cependant en vigueur à titre transitoire, le temps que le nouveau dispositif légal soit complété par les textes d’application.

5 Loi $\mathrm{n}^{\circ} 2019-675$ du 29 juillet 2019 portant code forestier, art. 62 et 63 . Voy. également les art. 2 et 6 du décret $n^{\circ}$ 2019-980 du 29 novembre 2019 relatifs à l'exploitation forestière dans le domaine national.

6 Décret $\mathrm{n}^{\circ}$ 94-368 du $1^{\text {er }}$ juillet 1994 portant modification du décret n 66-421 du 15 septembre 1966 réglementant l'exploitation des bois d'œuvre et d'ébénisterie, de service, de feu et à charbon, art. 11. 


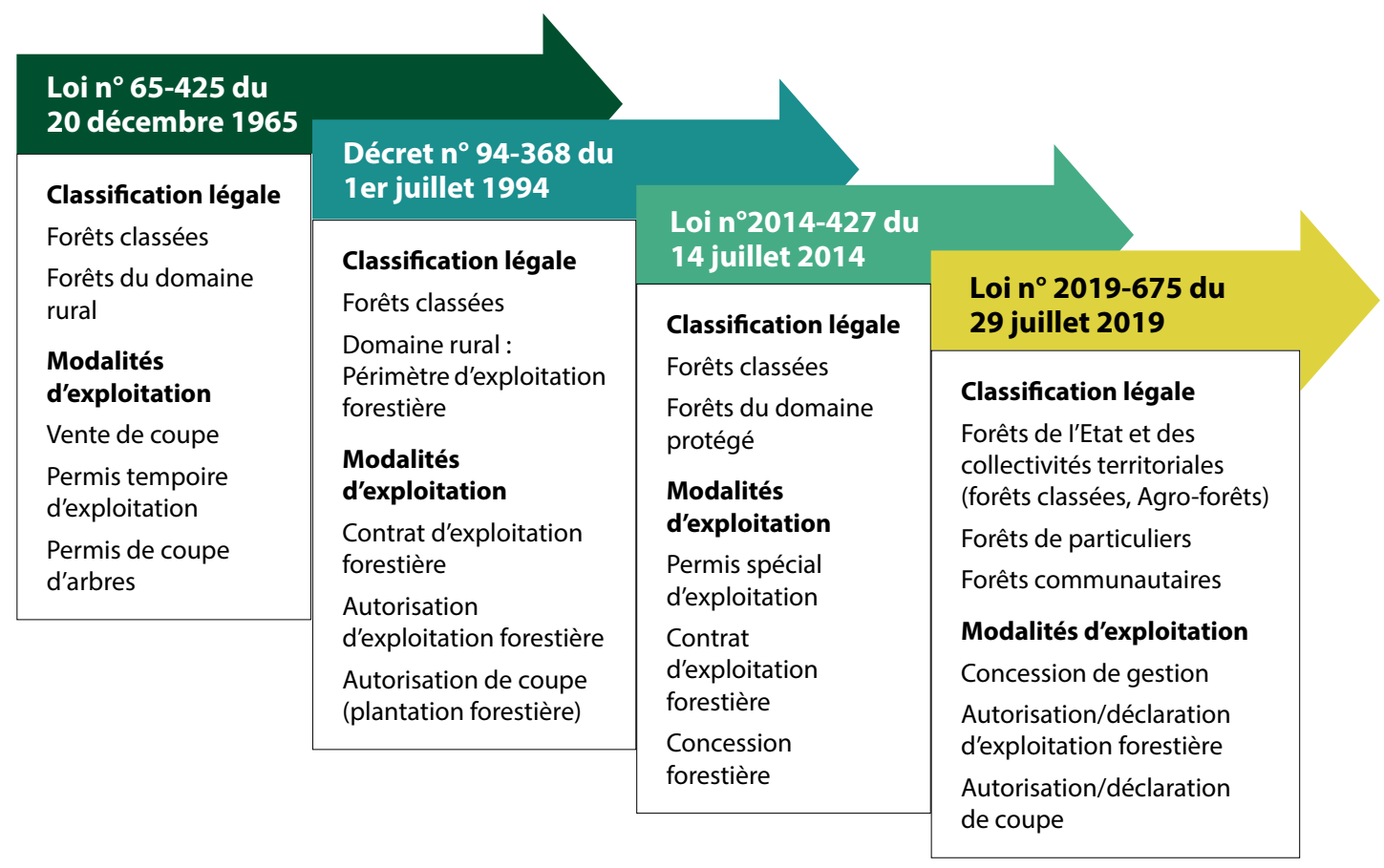

Figure 3.12 Législation sur la provenance du bois

Sous l'ancienne loi forestière et les décrets subséquents, le bois légal ne pouvait provenir que des PEF ou des forêts classées de la SODEFOR. Ces espaces sont réservés aux usines de transformation agréées à l'exploitation forestière, à des groupements d'exploitants et aux individus justifiant des ressources financières et matérielles nécessaires à une exploitation de type industriel. L'essentiel de la production de sciages légaux provient des PEF. La production des plantations est quant à elle marginale et repose sur deux essences, en loccurrence le Teck (Tectona Grandis) et le Gmélina (Gmelina arborea). Hormis quelques fluctuations consécutives à la période de crise politique de 2011, la production légale est restée relativement stable au fil des ans.

Pour les besoins de satisfaction de la demande nationale, les usines de transformation de bois d’œuvre et d'ébénisterie, les autorisations spéciales, les permis de bois de coupe et les autorisations d'exploitation des produits secondaires ont été répertoriés comme sources uniques d'approvisionnement du marché local ${ }^{7}$. Les sources d'approvisionnement autorisées ont vocation, en théorie tout au moins, à mettre du bois à la disposition des dépôts, des entrepôts et des ateliers spécialisés dans la commercialisation des produits forestiers. Dans cette perspective, le décret $n^{\circ} 73-490$ du 11 octobre 1973 oblige les unités de transformation à mettre une partie de leur production sur le marché national ${ }^{8}$. Cette exigence n’a jamais été suivie du texte d'application définissant les quotas applicables, de même que l'obligation de déclaration des volumes mis en vente n’a jamais été exécutée de manière systématique par les industriels.

7 Arrêté $\mathrm{n}^{\circ} 00624$ du 24 novembre 2011 modifiant l'arrêté $\mathrm{n}^{\circ} 00505$ du 15 septembre 2011 portant identification de l’origine légale et traçabilité des produits forestiers commercialisés en Côte d'Ivoire, art. 5.

8 Décret $\mathrm{n}^{\circ} 73-490$ du 11 octobre 1973 portant obligation aux entreprises de première transformation du bois d’assurer l'approvisionnement du marché local en produits semi-finis, art. 1 et 2. 


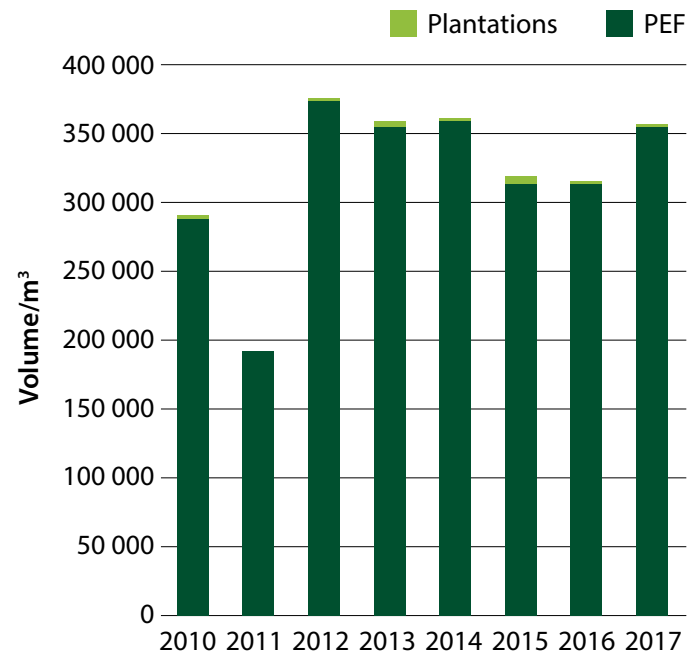

Figure 3.13 Production de sciages légaux

Source: MINEF

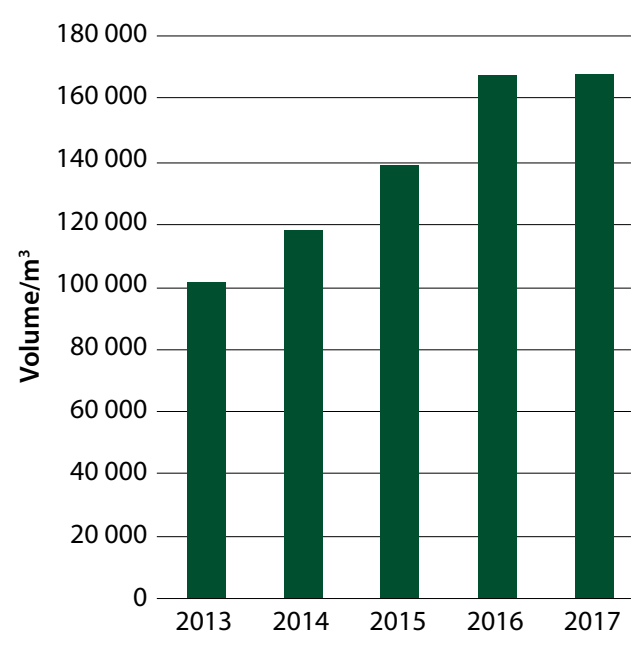

Figure 3.14 Ventes locales de sciages industriels Source: MINEF

Le volume de bois légal vendu sur le marché local est diversement estimé selon les sources convoquées. Les chiffres officiels du ministère des eaux et forêts (MINEF) faisaient état d'un volume de $41187 \mathrm{~m}^{3}$ pour l'année 2008, tandis que les professionnels du secteur évoquaient un volume de $350000 \mathrm{~m}^{3}$ pour la même année (Finifter, 2010). En 2014, les statistiques du MINEF avançaient un volume de vente local de $101023,041 \mathrm{~m}^{3}$ représentant environ 15 pour cent de la production nationale de sciages (MINEF 2014). Les volumes de sciages vendus localement ont progressivement évolué pour se situer à environ $168000 \mathrm{~m}^{3}$ en 2017.

Cette évolution sensible est probablement une conséquence de l'entrée en vigueur du règlement sur le bois de l'Union européenne (RBUE) et des tensions sur le marché international du bois. Les deux phénomènes ont amené les industriels qui ne pouvaient pas s’arrimer à la nouvelle réglementation à se tourner davantage vers le marché local. Durant les entretiens, plusieurs industriels ont affirmé qu'une partie de leur production était déjà commercialisée sur le marché local. Pour ces industriels, "le local c'est l'avenir de la filière", à condition que le cadre réglementaire soit incitatif.

\subsubsection{Compétitivité des sciages industriels sur le marché local}

Lapprovisionnement du marché domestique en sciage d'origine industrielle et donc a priori légale se heurte à plusieurs difficultés, au demeurant communes aux pays producteurs de bois d'Afrique centrale et de l'ouest. La première contrainte est liée à la faible rentabilité financière des sciages industriels sur le marché local. Au Ghana où les prix des sciages à l'exportation servent de référence pour l'Afrique de l'ouest, il apparaît que le marché international est de loin plus rémunérateur que le marché national (OIBT, 2019). Les prix de vente des sciages industriels à l'exportation sont entre 70 et 80 pour cent plus élevés que ceux pratiqués sur le marché local, ce qui les met quasiment hors de portée de la majorité 


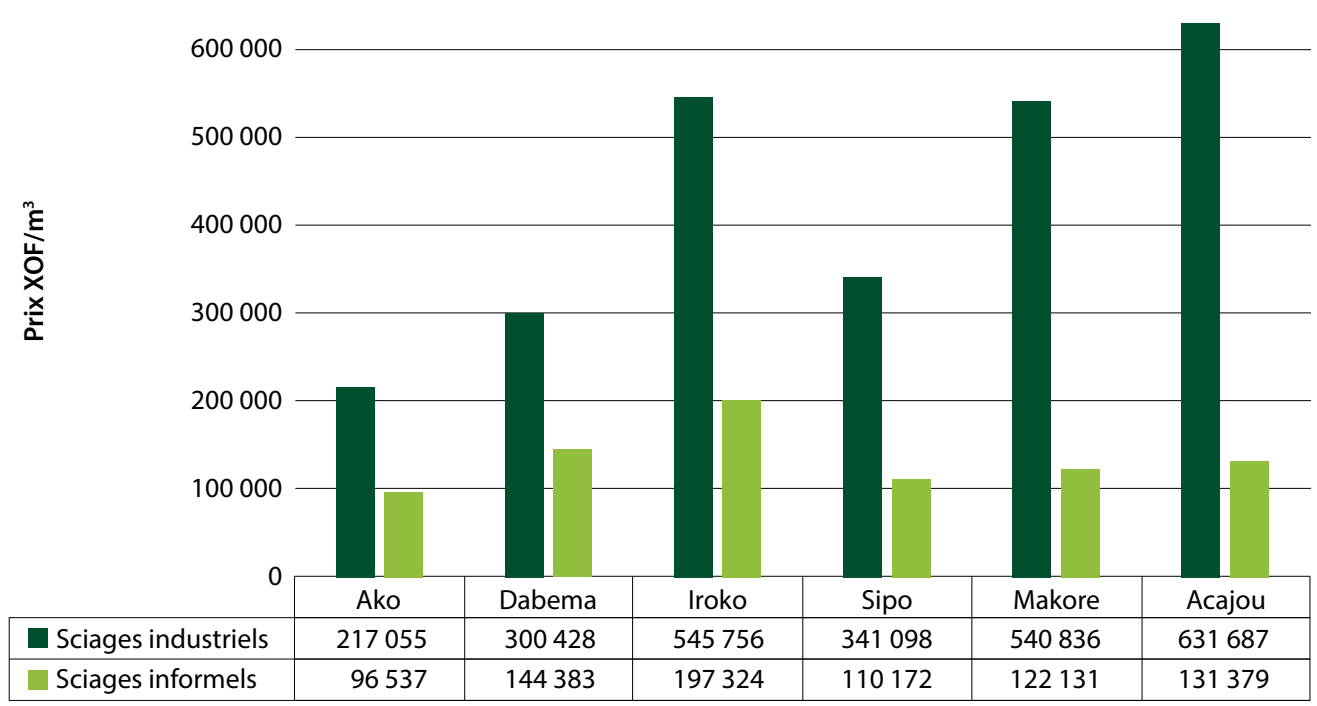

Figure 3.15 Prix des sciages à l'exportation

Sources: CIFOR et OIBT

de la demande nationale (figure 3.15). Avec de tels écarts, il est peu probable que les sciages industriels soient compétitifs sur le marché local face à des sciages artisanaux qui ne sont pas assujettis à l'impôt. Cela est d'autant plus vrai en l'absence de sensibilité pour les produits légaux ou durables de la part des consommateurs, qu'il s'agisse de particuliers, ou comme tend à le montrer cette étude, d'institutions publiques.

La deuxième contrainte tient à la rareté des essences qui entraîne une compétition entre le marché local et le marché international. Pour certains industriels rencontrés, des essences comme l'Iroko, l'Acajou ou le Lingué sont tout simplement exclus du marché local, du moins pour les sciages qui sont considérés comme du "premier choix". Il se trouve précisément que pour ce type d'essences, les consommateurs, au rang desquels les menuisiers-ébénistes, ne veulent pas de produits de second choix. Mais comme le souligne Cerutti et al., il n'existe quasiment plus d'essences sans intérêt pour les industriels (Cerutti et al., 2015). Les principales essences forestières que l'on retrouve sur le marché sont quasiment les mêmes que celles qui sont valorisées par les industries forestières.

Plusieurs opérateurs déclarent mettre une partie de leur production sur le marché local. Les coûts d’exploitabilité étant plus élevés, les sciages industriels de second choix s'avèrent logiquement plus élevés que les prix pratiqués pour les sciages artisanaux (figure 3.17) et pour les sciages industriels dont les revendeurs ne payent pas de taxes.

La troisième difficulté à l'approvisionnement réside dans les coûts de production. Le coût de production des sciages industriels est bien plus élevé en raison de la fiscalité, des coûts liés à l'acquisition de la ressource, du transport et du séchage. Lacquisition de la ressource, 


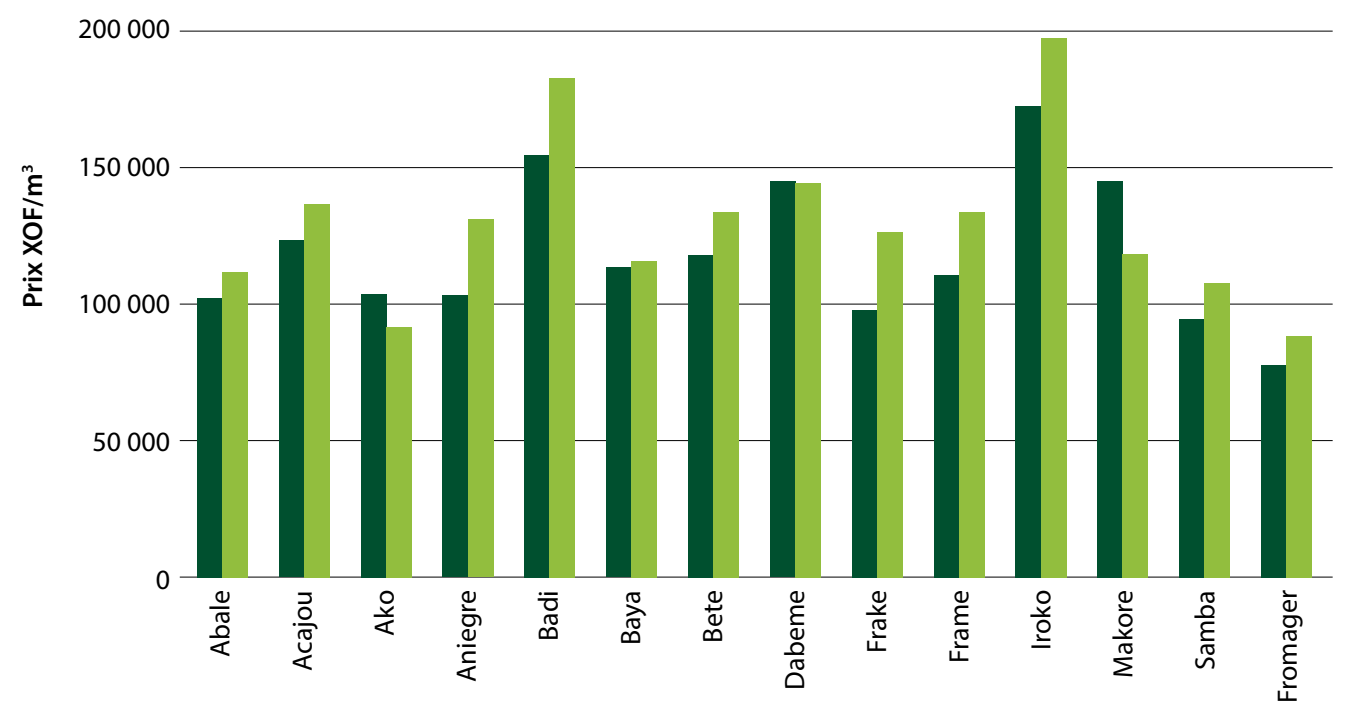

Figure 3.16 Principales essences commercialisées

Sources: CIFOR et OIBT

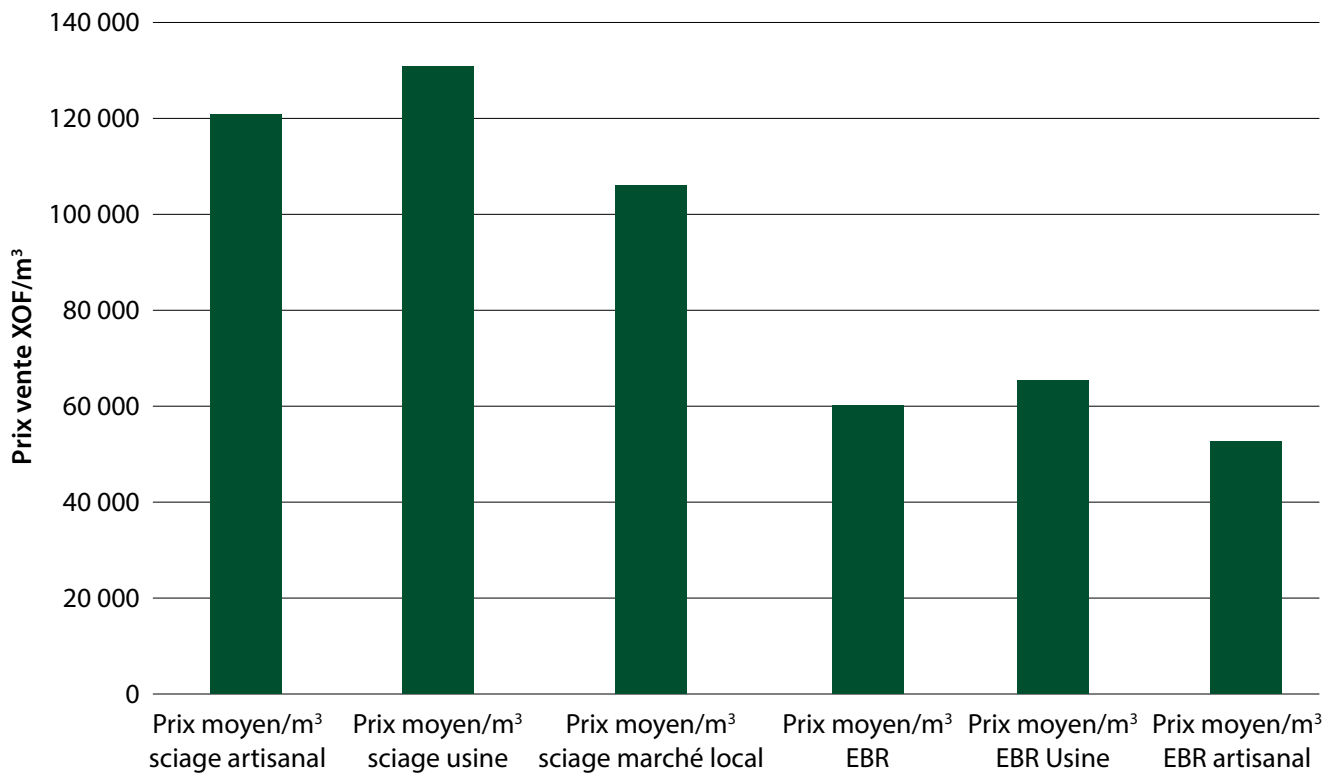

Figure 3.17 Prix de vente moyen des sciages sur le marché local

Sources: CIFOR et OIBT 
l'exploitation et le transport représentent les postes de dépense les plus élevés. La rareté de la ressource oblige les unités de transformation à s'approvisionner auprès de périmètres éloignés de leur site de production, ce qui a pour effet d'accroître les coûts d'exploitation et de transport qui représentent 50 pour cent des charges. Il s'agit d'un problème crucial pour des Unités de transformation de bois (UTB), dans un environnement où les groupements d'exploitants nont aucune obligation légale à fournir leur production aux UTB. Pour ce qui est du séchage, contrairement aux pays d'Afrique centrale tels que le Cameroun où cette opération représente entre 3 et 4 pour cent, en Côte d'Ivoire, elle avoisine 29 pour cent du coût de production. Les tableaux 2 et 3 présentent la structure des coûts de production des sciages industriels à partir de deux cas. Le premier détaille les coûts de production standard pour des sciages destinés à l'exportation. L'estimation a pris comme référence un volume de $5664 \mathrm{~m}^{3}$ représentant la production annuelle de l'unité de transformation retenue. Le second tableau récapitule quant à lui les coûts de production à la sortie de l'usine pour des sciages à destination du marché local. Comme dans le cas précédent, l'estimation s'appuie sur la production annuelle de l'usine, soit $4600 \mathrm{~m}^{3}$.

\section{Tableau 3.2 Coûts de revient des sciages industriels (exportations)}

\begin{tabular}{lcc}
\hline Structure des coûts & Montant total (XOF) pour $\mathbf{5} 6 \mathbf{6 4} \mathbf{~ m}^{\mathbf{3}}$ de sciages & Coût $/ \mathbf{m}^{\mathbf{3}}$ (XOF) \\
\hline Fiscalité forestière & 34140599 & 6028 \\
\hline Exploitation & 650578096 & 114862 \\
\hline Transformation & 159381150 & 28139 \\
\hline Séchage & 411516320 & 72655 \\
\hline Contribution villageoise & 4305000 & 760 \\
\hline Autres coûts & 95673717 & 16892 \\
\hline Coûts de revient & 1355594881 & 239335 \\
\hline Marge (20\%) & 477056939 & 84226 \\
\hline Prix de vente & 2215214944 & 391104 \\
\hline
\end{tabular}

Certains industriels mettent entièrement leur production sur le marché local avec des prix à l'usine relativement proches de ceux des sciages informels (tableau 3.3). Mais le prix de ces produits augmente une fois sur le marché du fait de la chaîne d'intermédiaires. Le business model des industriels ne leur permet pas de vendre de faibles quantités aux acheteurs individuels. De ce fait, le marché du sciage industriel est monopolisé par des négociants. Ces intermédiaires sont le passage obligé pour l'accès au bois légal car ils disposent des ressources financières nécessaires pour obtenir le bois auprès des industriels, contrairement aux artisans.

La quatrième difficulté pour les entreprises industrielles à mettre du bois légal sur le marché local est liée à la qualité des produits disponibles. Les industriels mettent sur le marché des produits qualifiés de "second choix" au minimum, sinon de troisième choix, voire de 
Tableau 3.3 Coûts de revient des sciages industriels (ventes locales)

\begin{tabular}{|c|c|c|}
\hline Structure des coûts & $\begin{array}{l}\text { Montant total (XOF) } \\
\text { pour } 4600 \mathrm{~m}^{3} \text { / Sciages }\end{array}$ & Coût $/ \mathrm{m}^{3}$ (XOF) \\
\hline \multicolumn{3}{|l|}{ Procédure d'acquisition/Renouvellement PEF } \\
\hline \multicolumn{3}{|l|}{ Constitution du dossier administratif } \\
\hline Agrément à la profession d'exploitant forestier & 6000000 & 1304 \\
\hline \multicolumn{3}{|l|}{ Agrément à la transformation du bois } \\
\hline Reboisement & 8750000 & 1902 \\
\hline \multicolumn{3}{|l|}{ Charges liées à l'exploitation du bois } \\
\hline Achat des grumes & 15000000 & 3260 \\
\hline Consommables (Carburant, huile) & 18450000 & 4010 \\
\hline Coût de transport (chantier - scierie) & 75000000 & 16304 \\
\hline Location bull & 37500000 & 8152 \\
\hline Autres frais d'exploitation & 32400000 & 7043 \\
\hline \multicolumn{3}{|l|}{ Charges liées à la transformation du bois (sciage) } \\
\hline Électricité & 16800000 & 3652 \\
\hline Consommables (Carburant, huile) & 33210000 & 7219 \\
\hline Pièces de rechange & 14400000 & 3130 \\
\hline Amortissement chargeuse & 3500000 & 760 \\
\hline Personnel de production & 78000000 & 16956 \\
\hline Amortissement matériel de production & 22500000 & 4891 \\
\hline \multicolumn{3}{|l|}{ Fiscalité } \\
\hline Taxe d'attribution & 2687088 & 584 \\
\hline Taxe d'intérêt général & 1743020 & 378 \\
\hline Taxe d'abattage & 14680000 & 3191 \\
\hline Fiscalité générale & 15180000 & 3300 \\
\hline Charges sociales & 11700000 & 2543 \\
\hline \multicolumn{3}{|l|}{ Transport } \\
\hline Transport & 30000000 & 6521 \\
\hline Coût de revient & 437500108 & 95108 \\
\hline Prix de vente & 529000000 & 115000 \\
\hline
\end{tabular}

déchets pour les raisons évoquées précédemment. De tels produits n'attirent pas les artisansmenuisiers. La qualité concerne également les essences disponibles. Les habitudes de consommation amènent les artisans-menuisiers à solliciter des essences que les industriels privilégient en raison de leur plus-value sur le marché international. L'indisponibilité de ces essences conduit nécessairement ces acteurs à se tourner vers le sciage clandestin afin de répondre aux besoins de leur clientèle 


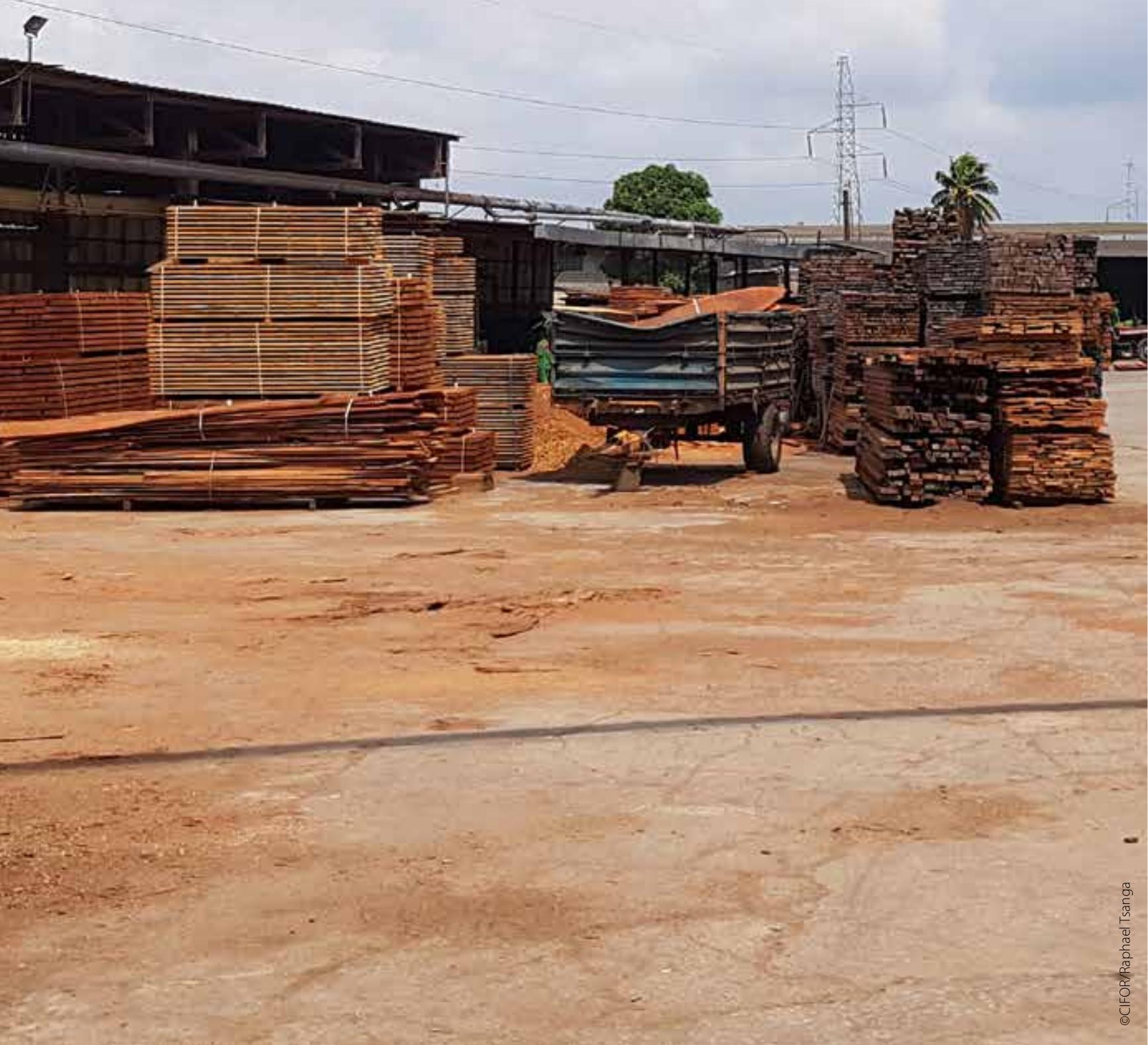




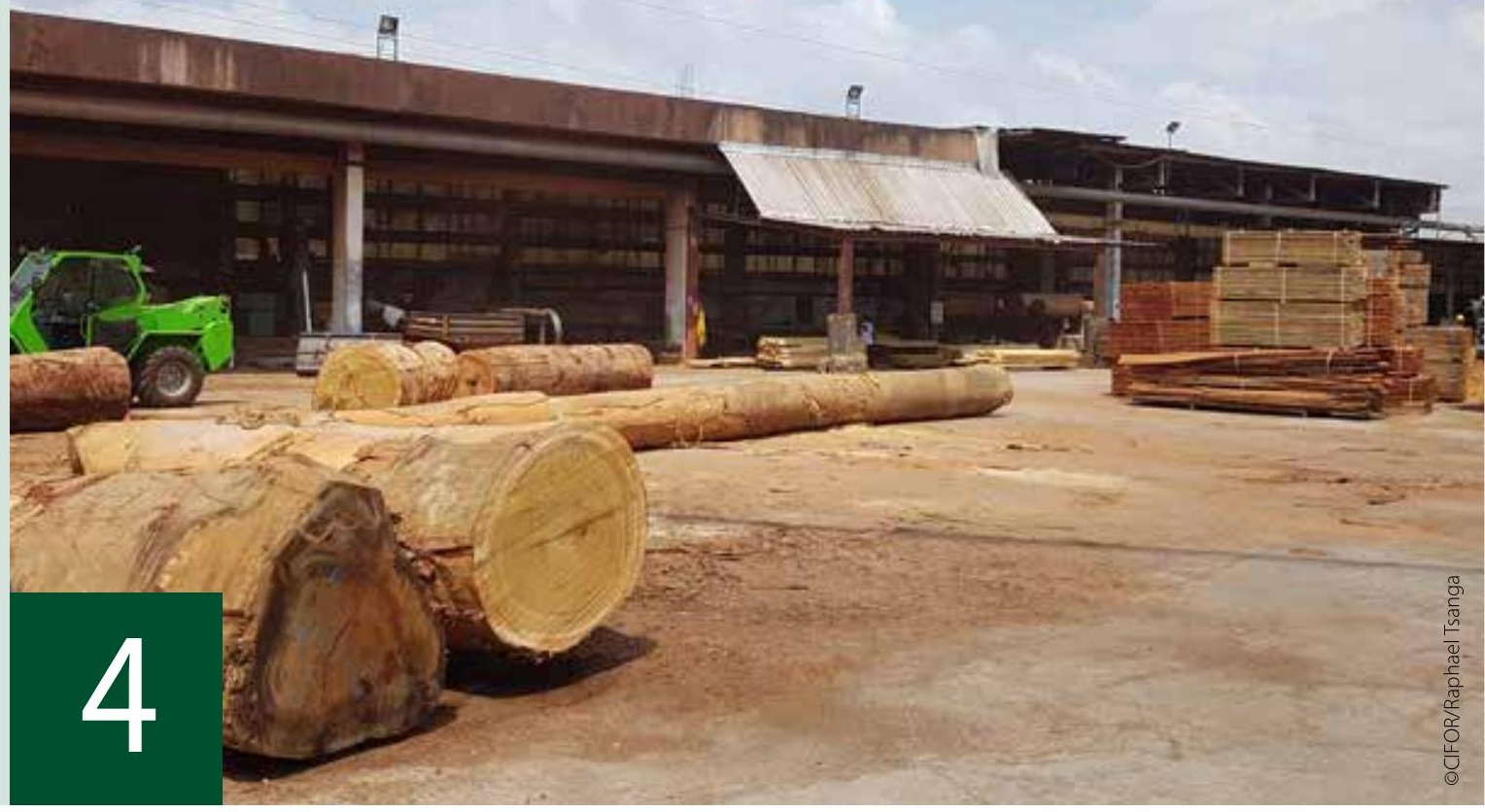

\section{Conclusion et recommandations pour l'approvisionnement du marché local en bois légal}

En Côte d'Ivoire, la réglementation prévoit depuis plusieurs décennies déjà que les exploitants forestiers industriels approvisionnent le marché local sous peine de sanctions. À lévidence, cette disposition n’a jamais été effective. Les volumes de bois légal mis sur le marché national par les industriels sont très loin de satisfaire à la demande nationale aussi bien en matière de qualité que de quantité. Les innovations apportées par la nouvelle législation pourraient contribuer à améliorer l'offre de bois légal dans la mesure où la disparition programmée des PEF ouvre la voie à la restructuration du domaine forestier national. Le nouveau code forestier crée des forêts de collectivités territoriales et des agro-forêts qui devraient être exploitées sur la base de plans d’aménagement. Une troisième catégorie constituée de forêts communautaires a également été instituée et sera exploitée selon toute vraisemblance sur la base d'un plan de gestion simplifié. En outre, les communautés locales seront en droit de solliciter des concessions dans les forêts classées. Si le processus de réforme est conduit jusquà son terme, les forêts communautaires pourraient constituer une source d'approvisionnement du marché local à côté des opérateurs industriels traditionnels. La localisation de ces forêts dans le domaine rural où la configuration de l'écosystème est propice à des modes d'exploitation de type coupe de bois. Au-delà de l'exploitation des forêts naturelles, la pérennité de la filière bois est largement tributaire de la reconstitution du capital forestier. Dans la perspective de la nouvelle loi, les plantations forestières devraient constituer la principale de source de bois légal 
sur le long terme. L'incitation des acteurs privés et des collectivités territoriales à investir dans les plantations, couplée à la consécration d'un droit de préemption sur les reboisements compensatoires en faveur des exploitants forestiers devrait augmenter l'offre de bois légal à moyen terme.

En l'état actuel de la réglementation, trois principales sources sont susceptibles d’approvisionner le marché local en bois d’origine légale. Il s'agit des périmètres d'exploitation forestière, des forêts classées et des plantations forestières. Ces trois sources font face à un manque de ressources forestières qui contribue à accroître la compétition entre le marché national et le marché international et favorise dans une certaine mesure la prolifération des sciages d'origine illégale. L’une des questions cruciales qui déterminera l'évolution future d'une politique d'achat de bois légal sera précisément la disponibilité du bois légal sur le marché. Plusieurs options sont envisageables pour répondre à cette problématique.

\subsection{Optimiser l'utilisation de la ressource existante}

Traditionnellement, les normes d'exploitation forestière prescrivent l'abandon des coursons une fois les grumes récupérées. Or, dans un contexte de rareté de la ressource, ces rebuts de l'exploitation forestière sont susceptibles d'être valorisés afin de renforcer l'offre de bois existante. Le cadre juridique n’offre pas suffisamment de clarté quant à la possibilité ou non de valoriser cette ressource. De la même manière, le potentiel de cette ressource est très mal connu. Des travaux supplémentaires pour situer le volume qui peut être généré avec la valorisation de cette ressource seraient pertinents. Plusieurs scénarios sont possibles pour valoriser les coursons. Le premier est celui d'une autorisation d'exploitation des rebuts par les industriels. Il présente l'avantage de garantir un meilleur contrôle de la ressource, lopérateur en charge de la valorisation étant également responsable de la gestion du PEF.

Le second scénario consisterait à autoriser les exploitants artisanaux ou semi-industriels à récupérer les rebuts à l'intérieur des PEF sous le contrôle de l'administration ou des titulaires de périmètre ou à l'extérieur des $\mathrm{PEF}$, cette dernière hypothèse étant nécessairement onéreuse pour les opérateurs industriels. Au-delà de l’amélioration de l’offre en bois, la valorisation par les artisanaux où les semi-industriels a le potentiel de ramener à la baisse les coûts de production, puisque dans ce cas précis la taxe d'abattage aura déjà été acquittée par le titulaire du PEF. Ne subsisteront alors que les coûts d'accès à la ressource et de transformation.

Le deuxième niveau d'optimisation de l'utilisation de la ressource disponible porte sur les chutes de bois. Plusieurs sites industriels disposent des équipements permettant la fabrication du bois de récupération. Ce type de produits constitue une opportunité qui pour le moment n'est pas suffisamment diffusée auprès des menuisiers et des consommateurs finaux en raison des prix de vente encore élevés pour le moment sur le marché local. 


\subsection{Diminuer les coûts de revient des sciages industriels}

Largument fiscal est le plus souvent évoqué par les industriels pour justifier le coût élevé du bois légal. Si cet argument ne manque pas de fondement, plusieurs facteurs autres que la seule fiscalité peuvent expliquer le caractère onéreux du bois légal industriel. Dans nombre de pays forestiers, le transport est l'un des postes de dépenses les plus importants, représentant de 24 à 44 pour cent des charges d'exploitation, suivi de l'achat de la matière première, rubrique pouvant atteindre jusquà 75 pour cent des charges de l'opérateur (Roda, 2006). Cette contrainte est également présente en Côte d'Ivoire où nombre d'usines sont en surcapacité et font face à des difficultés d'approvisionnement. Des incitations fiscales telles que la taxe sur la valeur ajoutée pourraient être envisagées pour les produits à destination du marché local. Les incitations fiscales doivent être couplées avec l'encouragement des groupements d'exploitants à approvisionner les usines situées dans leur environnement immédiat de manière à diminuer les coûts de transport. Sur ce point précis, les unités industrielles ont maintenu un fonctionnement similaire à celui de la période où la matière première était disponible en abondance. L'outil industriel n’a donc pas suffisamment évolué pour prendre en compte la nouvelle configuration du secteur forestier. Un redimensionnement des unités de production industrielle aurait pour effet d'agir sur les coûts.

\subsection{Fluidifier la chaîne d'approvisionnement du bois légal}

La chaîne d'approvisionnement se distingue par les positions monopolistiques détenues par certains acteurs qui détiennent un pouvoir d'immobilisation important du fait de leurs capacités financières. L'acquisition préemptive de la matière première génère inévitablement des coûts supplémentaires pour le consommateur final. Il faudrait par conséquent poser les bases d'un partenariat entre le secteur industriel et celui des artisans menuisiers. Ce partenariat peut prendre la forme de centrales d'achats auprès desquelles les artisans menuisiers pourraient s'approvisionner.

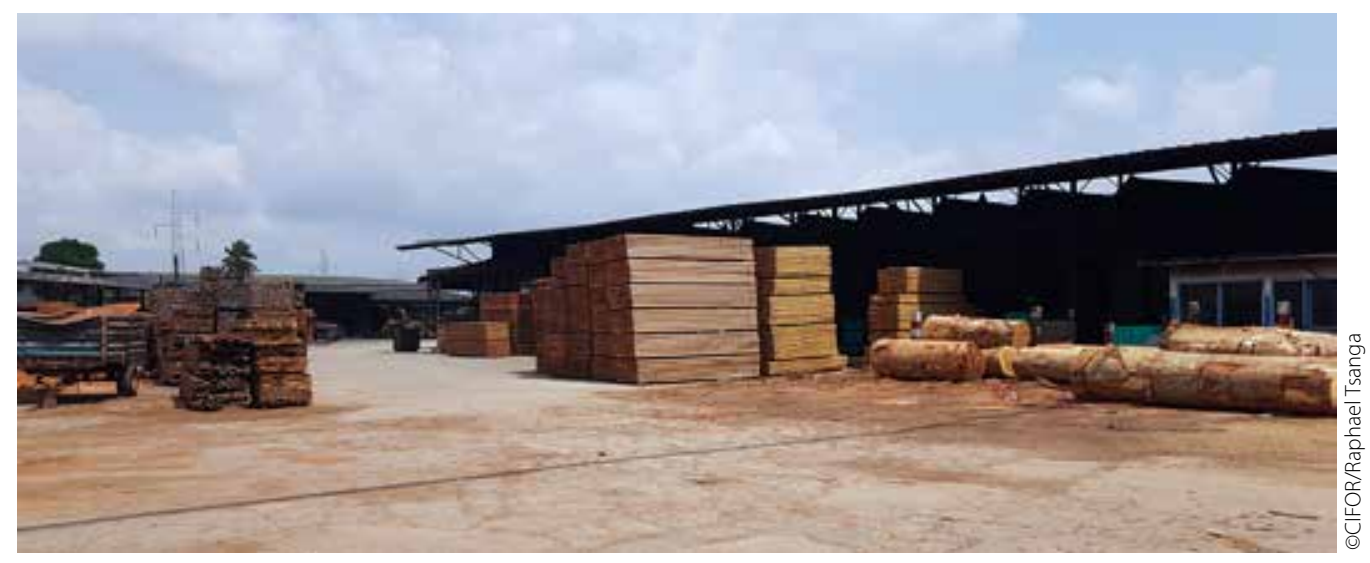

Vue d'un site industriel de transformation de bois 


\subsection{Envisager la mise en place d'une politique publique d'achat de bois légal}

La valeur des marchés publics programmés en Côte d'Ivoire en 2017 était estimée à 2530 milliards de XOF, soit environ 11 pour cent du produit intérieur brut (PIB) de l'État de Côte d'Ivoire au cours de cette même année. Le nombre de marchés approuvés se situe quant à lui autour de 915,8 milliards. Ceci représente, pas moins de 7225 marchés prévisionnels qui regroupent l'ensemble des besoins exprimés par les services de l'État en termes de fourniture de biens, services et travaux. Une partie de cette commande nécessite inévitablement le recours au bois et ainsi qu’aux produits dérivés pour son exécution.

Une des approches qui pourrait améliorer l'offre de bois légal sur le marché est la mise en place d'une politique publique d'achat qui obligerait ou inciterait les cocontractants de l'État et ses démembrements techniques ou territoriaux à s'approvisionner auprès de sources autorisées lorsqu'ils sont amenés à utiliser le bois dans l’exécution des marchés publics. La consommation des acteurs publics est certes marginale si on la compare aux flux de bois qui circulent sur le marché national, mais au regard de l'importance financière des marchés publics, elle peut contribuer à transformer les habitudes du secteur privé. La mise en place d'une telle politique fera nécessairement face à au moins trois défis, à savoir: (i) le problème d'une offre de bois légal relativement faible et à des coûts prohibitifs, (ii) des surcoûts potentiels pour le budget de l'État et des collectivités locales et (iii) le risque de captation de cette niche commerciale par les industriels et l'exclusion des opérateurs de la filière artisanale.

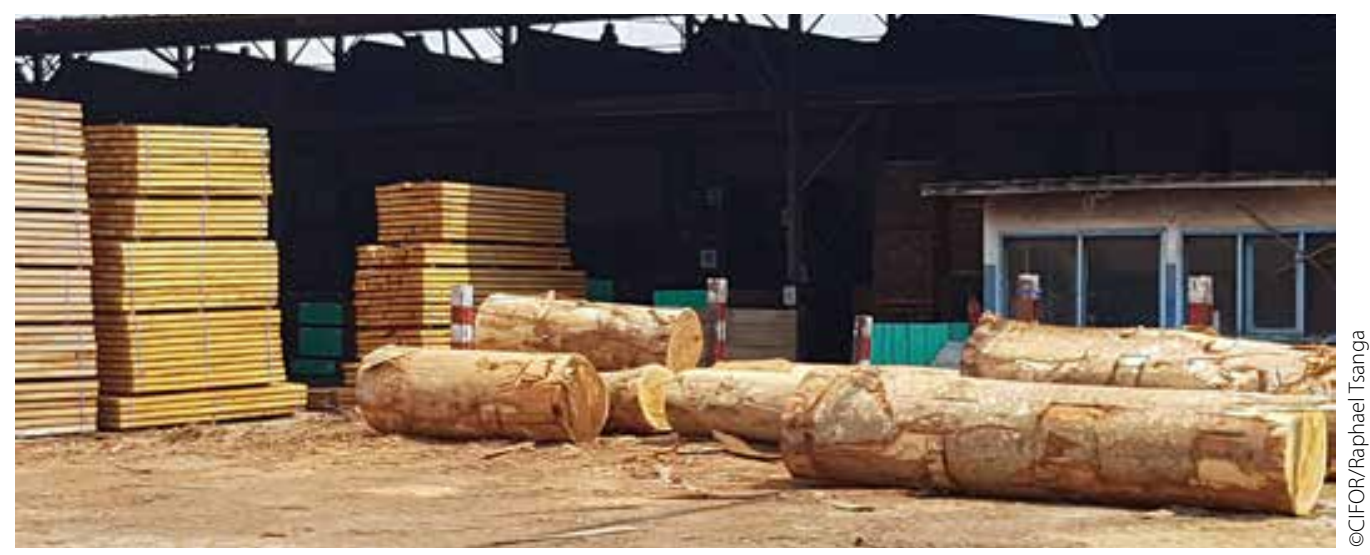

Colis de bois prêts pour l'exportation.

$\mathrm{Au}$-delà des options techniques décrites ci-dessus, l'engagement des acteurs politiques sera déterminant pour la mise en œuvre effective d'une filière de bois légale en Côte d'Ivoire. Le code des marchés publics ayant déjà posé les jalons pour des marchés publics durables, le renforcement de l'information et la sensibilisation des administrations sectorielles et des entités territoriales décentralisées est nécessaire afin que la consommation de bois et de produits dérivés de source légale soit érigée en pratique commune pour tous les acteurs publics. 
Commission des communautés européennes, 2001. Communication interprétative de la Commission sur le droit communautaire applicable aux marchés publics et les possibilités d'intégrer des considérations environnementales dans lesdits marchés.

Commission européenne, 2008. Communication de la Commission au Parlement européen, au Conseil, au comité économique et social européen et au comité des régions relative à des marchés publics pour un environnement meilleur.

Commission européenne, 2016. Acheter vert! Un manuel sur les marchés publics écologiques. Commission européenne, 2017. Fiche thématique du semestre européen: les marchés publics. Finifter, R. 2010. L'industrie du bois en Côte d'Ivoire: Note d'orientation politique.

FMI, 2019. Côte d'Ivoire : Cinquièmes revues de l'accord au titre de la facilité élargie de crédit et de laccord élargi au titre du mécanisme élargi de crédit (No. 19/197). Fonds monétaire international, Washington D.C.

Groupe de la Banque mondiale, 2016. Benchmarking Public Procurement 2016: Assessing Public Procurement Systems in 77 Economies. World Bank, Washington, DC.

Kataoka, A. 2006. IGPN and Green Purchasing Activities on Global Level.

Kishor, N. et Lescuyer, G. 2012. Controlling illegal logging in domestic and international markets by harnessing multi-level governance opportunities. International Journal of the Commons 6, 255- 270.

Lescuyer, G., Tsanga, R., Essiane Mendoula, E., Embolo Ahanda, B.X., Hadji Adama, O., Fung, O., Dubiez, E. et Bigombe Logo, P. 2016. Demandes nationales de sciages: Obstacle ou opportunité pour promouvoir l'utilisation des ressources forestières d'origine légale au Cameroun?

Louppe, D. et Ouattara, N. 2013. Étude sur l'exploitation forestière et les contraintes d'une gestion durable des forêts dans le domaine rural en Côte d'Ivoire. Côte d'Ivoire.

MINEF. Arrêté $n^{\circ} 00624$ du 24 novembre 2011 modifiant l'arrêté $n^{\circ} 00505$ du 15 septembre 2011 portant identification de l'origine légale et traçabilité des produits forestiers commercialisés en Côte d'Ivoire.

MINEF. Arrêté n 911 MINEFOR-DIF-DCFC du 25 juin 1983 portant classement des permis forestiers.

MINEF. Décret $n^{\circ} 73-490$ du 11 octobre 1973 portant obligation aux entreprises de première transformation du bois d'assurer l'approvisionnement du marché local en produits semi-finis.

Ministère du Commerce. Arrêté $n^{\circ} 006$ du 16-01-2015 définissant les modalités d'immatriculation au répertoire des entreprises artisanales.

Nogueron, R. et Cheung, L. 2014. Approvisionnement en bois produits légalement. Guide pour les entreprises.

OCDE, 2008. L'intégrité dans les marchés publics: Les bonnes pratiques de A à Z. OECD. https://doi.org/10.1787/9789264027534-fr

OIBT, 2019. Tropical Timber Market Report.

OMC, 2017. Examen des politiques commerciales: Côte d'Ivoire, Guinée-Bissau et Togo.

Parlement européen. Directive 2014/24/UE du Parlement européen et du Conseil du 26 février 2014 sur la passation des marchés publics.

PNUD, 2008. Achats écologiques. Guide pratique, Vol 1.

République de Côte d'Ivoire, 2019. Loi $n^{\circ} 2019-675$ du 29 juillet 2019 portant code forestier.

République de Côte d'Ivoire, n.d. Décret $n^{\circ}$ 2013-815 du 26 novembre 2013 portant interdiction du sciage à façon. 
République de Côte d'Ivoire. Décret $n^{\circ} 2009-259$ du 06 août 2009 portant Code des marchés publics.

République de Côte d'Ivoire. Décret $n^{\circ} 2013-815$ du 26 novembre 2013 portant interdiction du sciage à façon.

République de Côte d'Ivoire. Décret $n^{\circ} 2015-475$ du 1er juillet 2015 portant procédures et modalités de gestion des projets et programmes financés ou cofinancés par les partenaires techniques et financiers.

République de Côte d'Ivoire. Décret $n^{\circ} 2019$ - 828 du 9 octobre 2019 portant modalités de création des agro-forêts.

République de Côte d'Ivoire. Décret $n^{\circ}$ 2019-977 portant procédures de classement des forêts et des agro-forêts.

République de Côte d'Ivoire. Décret $n^{\circ} 2019-978$ relatif à la concession de la gestion $\mathrm{du}$ domaine forestier privé de l'État et des collectivités territoriales.

République de Côte d'Ivoire. Décret $n^{\circ} 2019-980$ du 29 novembre 2019 relatif à l'exploitation forestière dans le domaine national.

République de Côte d'Ivoire. Décret $n^{\circ} 94-368$ du 1er juillet 1994 portant modification $d u$ décret $n^{\circ}$ 66-421 du 15 septembre 1966 réglementant l'exploitation des bois d'ouvre et d'ébénisterie, de service, de feu et à charbon.

République de Côte d'Ivoire. Décret $n^{\circ}$ 94-377 du 1er juillet 1994 portant modification des valeurs mercuriales sur le bois en grumes et certains produits ligneux à l'exportation.

République de Côte d'Ivoire. Loi n ${ }^{\circ} 2014-338$ du 05 Juin 2014 à relative à l'artisanat.

République de Côte d'Ivoire. Loi $n^{\circ} 2014-390$ du 20 juin 2014 d’orientation sur le développement durable.

République de Côte d'Ivoire. Loi n ${ }^{\circ} 2014-427$ du 14 juillet 2014 portant code forestier.

République de Côte d'Ivoire. Loi $n^{\circ}$ 65-425 du 20 décembre 1965 portant Code forestier.

République de Côte d'Ivoire. Loi n ${ }^{\circ}$ 96-766 du 3 octobre 1996 portant Code de l'Environnement.

République de Côte d'Ivoire. Ordonnance n²019-679 du 24 juillet 2019 portant code des marchés publics.

Roda, J.-M. 2006. Diagnostic économique et fiscal de la filière bois au Cameroun.

Testa, F., Iraldo, F., Frey, M. et Daddi, T. 2012. What factors influence the uptake of GPP (green public procurement) practices? New evidence from an Italian survey. Ecological Economics 82, 88-96. https://doi.org/10.1016/j.ecolecon.2012.07.011 


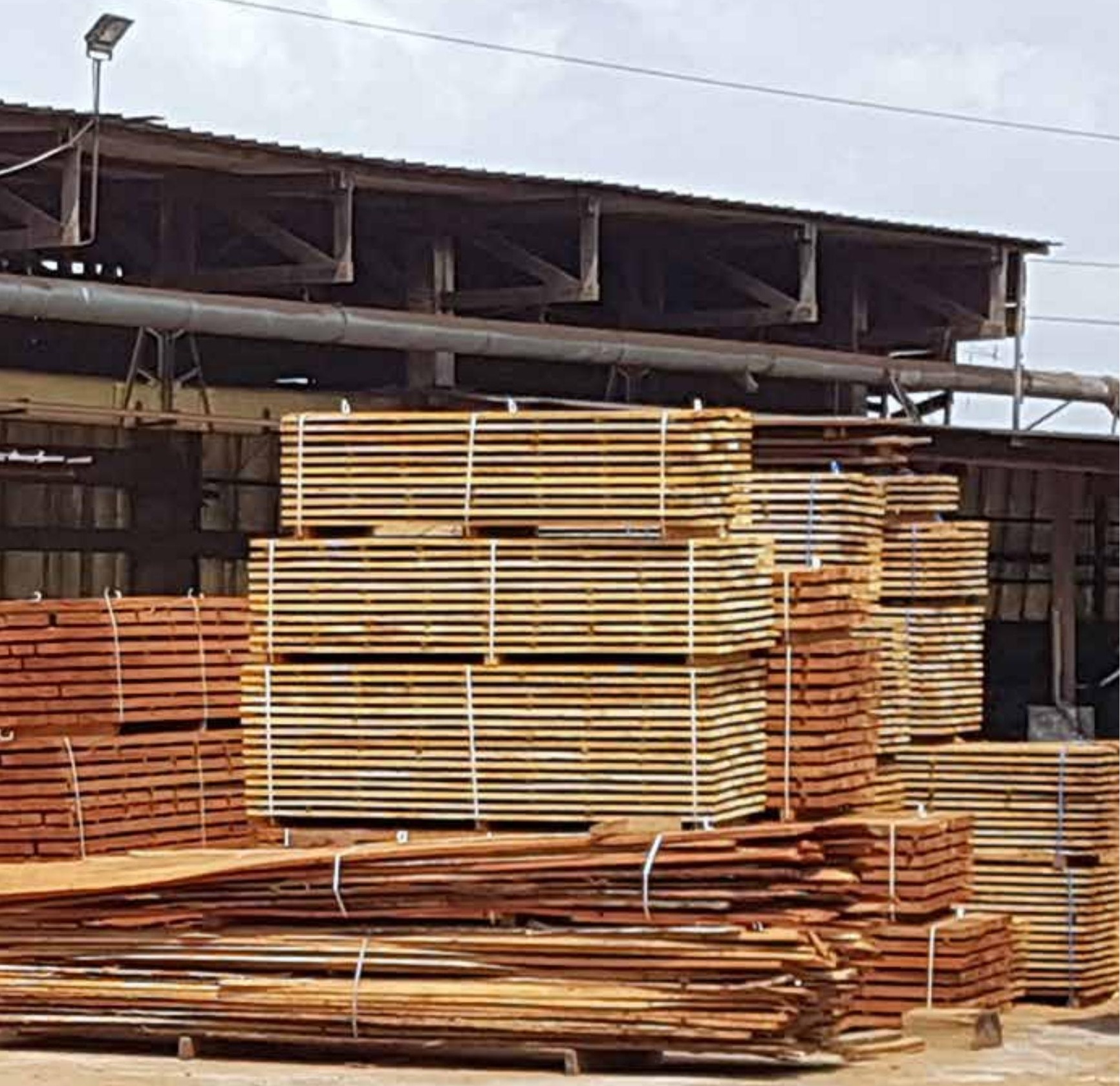


Depuis 2013, la Côte d'Ivoire est engagée dans la négociation d'un Accord de Partenariat Volontaire avec l'Union européenne (UE) dont l'objectif est d'endiguer l'exportation de bois d'origine illégale vers I'UE et la circulation de celui-ci sur le marché national. L'État et les collectivités territoriales contribuent indirectement à cette exploitation illégale à travers la consommation des produits forestiers d'origine incertaine dans le cadre des marchés publics.

Sur la période 2015-2018, les marchés publics ont absorbé en moyenne environ $342000 \mathrm{~m}^{3}$ en équivalent bois rond, répartis entre l'État et les collectivités territoriales. L'essentiel de la consommation publique de sciages est constitué de travaux de construction et de réhabilitation des infrastructures et par l'acquisition de mobilier.

L'offre moyenne de sciages légaux est d'environ $322000 \mathrm{~m}^{3}$ par an, dont la grande majorité est exportée vers les marchés occidentaux. Cette offre provient à titre principal des périmètres d'exploitation forestière qui fournissent 90 pour cent de la production bois légal et des forêts classées de la SODEFOR dont la production reste marginale.

Les volumes de sciages légaux vendus localement étaient estimés à environ $168000 \mathrm{~m}^{3}$ en 2017. Les sciages légaux font face à de réels problèmes de compétitivité sur le marché local. Les prix de vente des sciages industriels à l'exportation sont entre 70 et 80 pour cent plus élevés que ceux pratiqués sur le marché local, ce qui les met quasiment hors de portée de la majorité de la demande nationale.

La faible pénétration des bois légaux dans la sphère publique est révélatrice de la faible disponibilité du bois légal dans les marchés locaux. Plusieurs options techniques et politiques sont envisageables pour agir sur les volumes et les coûts de production. Les mesures possibles consistent à (i) optimiser l'utilisation de la ressource existante, (ii) diminuer les coûts de revient des sciages industriels, (iii) fluidifier la chaîne d'approvisionnement du bois légal et (iv) mettre en place une politique publique d'achat de bois légal.

fao.org

Recherche financée par:

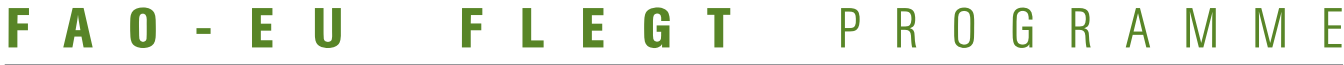

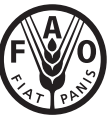

Organisation des Nations Unies pour l'alimentation et l'agriculture
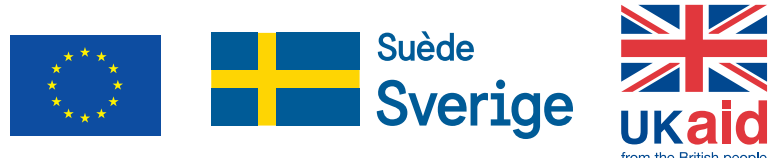

Cette activité est financée par l'Agence suédoise de coopération internationale, le département britannique du Développement international et l'Union européenne. Les opinions exprimées ici ne peuvent en aucun cas être considérées comme reflétant l'opinion officielle de l'Agence suédoise de coopération internationale, du département britannique du Développement international ou de l'Union européenne.

ISBN 978-92-5-133333-4 